\title{
EL SENADO EN LA JURISPRUDENCIA DEL TRIBUNAL CONSTITUCIONAL
}

\author{
M. ${ }^{a}$ ISABEL MARTÍN DE LLANO \\ Profesora Asociada de Derecho Constitucional \\ UNED \\ MARÍA SALVADOR MARTÍNEZ \\ Profesora Ayudante de Derecho Constitucional \\ UNED
}

\author{
SUMARIO \\ I. El Estatuto de los Senadores. \\ II. Organización interna y funcionamiento \\ del Senado. \\ III. Funciones y competencias del Senado. \\ IV. Derecho Procesal Constitucional y Senado. \\ V. Anexo.
}

Este trabajo tiene por objeto ofrecer un breve análisis de las sentencias relativas al Senado emitidas por el Tribunal Constitucional a lo largo de los ya casi veinticinco años de su actividad. Estas sentencias constituyen un conjunto no excesivamente amplio pero sí suficientemente representativo de las principales cuestiones que afectan al Senado.

Tanto las dos Cámaras que integran las Cortes Generales como las Asambleas Legislativas de las Comunidades Autónomas tienen en común numerosos aspectos relativos al estatuto de sus miembros, organización y funcionamiento internos, así como funciones y competencias, de modo que algunos de los pronunciamientos del Tribunal Constitucional sobre el Senado son predicables también de las otras Cámaras legislativas y, por ello, forman parte de la que podríamos llamar ajurisprudencia en materia de derecho parlamentario común". Esta jurisprudencia se refiere, por ejemplo, a la adquisición de la condición de parlamentario, a las prerrogativas parlamentarias y a las competencias de las Mesas de las Cámaras. Así, un primer grupo de las sen- 
tencias relativas al Senado se refieren a estas cuestiones comunes y en ellas, unas veces el Tribunal ha seguido la jurisprudencia ya sentada en decisiones anteriores relativas a otras Cámaras legislativas, mientras que, otras veces, más de las que se podría pensar en un primer momento — dado el papel secundario que la Constitución atribuye al Senado respecto al Congreso-, ha aportado elementos determinantes para esa ujurisprudencia parlamentaria común" ${ }^{1}$.

Un segundo grupo de decisiones del Tribunal Constitucional estaría integrado por aquellas sentencias que se refieren a aspectos específicos del Senado. Son decisiones de ese tipo las relativas, por ejemplo, a la elección de los Senadores autonómicos, y, sobre todo, las relativas a las funciones y competencias de la Cámara Alta, ya que, de acuerdo con el modelo establecido por la Constitución, en el ejercicio de las funciones atribuidas a las Cortes Generales el Senado desempeña un papel muy diferente al que desempeña el Congreso.

\section{EL ESTATUTO DE LOS PARLAMENTARIOS}

El Estatuto de los Parlamentarios agrupa el conjunto de derechos, deberes y prerrogativas de los miembros del Parlamento; garantías que se disfrutan desde el momento en que se adquiere la condición de parlamentario. Sin embargo, previo a la adquisición de dicha condición, la Administración Electoral juega un papel fundamental puesto que su objetivo primordial es velar por la transparencia, objetividad e igualdad de toda contienda electoral; es decir, asegurar que el desarrollo de cualquier proceso electoral se produzca con todo rigor y escrupolosidad.

Con este fin, además de otras competencias, se reconoce a la Administración Electoral la capacidad para resolver, de forma individualizada, los contencioso electorales que se susciten en la aplicación e interpretación de la legislación electoral. De ahí que la interpretación que realice de determinados preceptos de la Ley Electoral sobrepase el plano de la legalidad ordinaria y adquiera relevancia constitucional, al afectar, en la mayor parte de los supuestos, a los derechos fundamentales que la Constitución garantiza en su artículo 23.

Por ello, como garante último del adecuado desarrollo del proceso electoral el Tribunal Constitucional tiene competencia para conocer de los recursos de amparo electoral que se sustancien ante él con el fin de tutelar el derecho de participación política reconocido en el artículo 23 de la Constitución. Así, se podrá recurrir en amparo contra las sentencias dictadas por el Juzgado de lo Contencioso-Administrativo en los recursos contra la proclamación de candidaturas y candidatos (art. 49 LOREG); o bien, recurrir en amparo las sentencias

1 Existen algunos trabajos recopilatorios de esta jurisprudencia, como los de A. ARCE JANARIZ, El Parlamento en los Tribunales. Prontuarios de jurisprudencia parlamentaria, 2004; y L. DE LA PEÑA RODRÍGUEZ, Derecho Parlamentario Español y Tribunal Constitucional, 1998. Vid. también F. Pau i Vall (coord.), Parlamento y Justicia Constitucional, 1997. 
recaídas en los procedimientos contencioso-electorales sobre la proclamación de electos (art. 114.2 LOREG) ${ }^{2}$.

\section{AdQUISICIÓN Y CONSERVACIÓN DE LA CONDICIÓN DE PARLAMENTARIO}

\subsection{Presentación de candidaturas electorales}

En relación a la forma en que deben presentarse las candidaturas electorales, el Tribunal Constitucional tuvo ocasión de pronunciarse en la STC 26/1994 al resolver el recurso de amparo electoral interpuesto contra la Sentencia del Juzgado de lo Contencioso-Administrativo que inadmitió la candidatura al Senado presentada por un partido político, al no considerar válida la presentación de la misma por Correo sin personación posterior del representante de la formación política ante la Junta Electoral Provincial.

El Tribunal Constitucional analizó si la LOREG permite que la presentación de candidaturas electorales pueda hacerse llegar a la Junta Electoral Provincial por cualquier medio, incluido el correo, o si, por el contrario, es necesaria la personación del representante de la formación política ante la Junta Electoral Provincial.

El Alto Tribunal entendió que del contenido del artículo 45 LOREG ("Las candidaturas, suscritas por los representantes de los partidos, federaciones $y$ coaliciones y por los promotores de las agrupaciones de electores, se presentarán ante la Junta Electoral competente entre el decimoquinto y el vigésimo día posteriores a la convocatoria), se deduce sin ningún género de dudas que la presentación de candidaturas ha de cumplir dos premisas básicas: realizarse en la propia Junta Electoral y en el plazo legalmente establecido.

En este caso el Tribunal consideró que el demandante de amparo había cumplido ambos requisitos del artículo 45 LOREG, no siendo exigible que la presentación de candidaturas deba hacerse personalmente. "Antes al contrario, el más eficaz ejercicio de los derechos de participación democrática consagrados en el artículo 23 CE autoriza a entender, en cambio, que la presentación puede ser efectuada a través de cualquier mecanismo que permita cumplir los dos presupuestos inexcusables del art. 45 LOREG ${ }^{3}$. Así, el Alto Tribunal entendió que el acuerdo de la Junta Electoral Provincial obedeció a una interpretación injustificadamente impeditiva del ejercicio del derecho de sufragio pasivo.

\subsection{Causas de inelegibilidad}

Respecto a las causas de inelegibilidad, que tienen por fin evitar que las personas que ocupan un determinado cargo público puedan prevalerse del mismo para participar en unas elecciones en una posición de clara ventaja

2 Conforme a la reforma de la LOREG introducida por la LO 8/1991, de 13 de marzo.

3 STC 26/2004, Fj. 7. 
frente a otros candidatos, el Tribunal Constitucional se ha pronunciado en dos ocasiones.

En la primera de ellas ${ }^{4}$ el Tribunal Constitucional estudió si las causas de inelegibilidad previstas en el Real Decreto-ley 20/1977, norma preconstitucional, eran aplicables a los altos cargos de la Administración Autonómica.

En primer lugar el Tribunal Constitucional hizo referencia al derecho electoral pasivo como el derecho del que pueden ser titulares aquellos ciudadanos en los que concurran los requisitos de capacidad y que no estén incursos en causa de inelegibilidad. "La elegibilidad se delimita por lo que dice el artículo 70.1 de la Constitución y, por remisión de la misma, por la Ley Electoral. Es la Ley, por tanto, quien respetando, por un lado, el contenido de inelegibilidad minimo que establece la norma constitucional y, por otro lado, y sin que quede afectada la esencia del derecho, configurará, desde esta vertiente, la elegibilidad, 5 .

Dado que la ley electoral prevista por el artículo 70.1 CE no había sido promulgada, era de aplicación el Real Decreto-ley 20/1977. Se trataba según el Alto Tribunal de una norma delimitadora negativamente del derecho de elegibilidad que en el caso que nos ocupa fue interpretada extensivamente por la Jurisdicción Contencioso-Administrativa. Extensión que vulneró de modo inmediato y directo el artículo 23.2 de la Constitución al impedir al recurrente en amparo participar como elegible en las elecciones al Senado.

Por otro lado, la segunda ocasión en la que el Tribunal Constitucional se pronunció sobre las causas de inelegibilidad, analizó si las mismas podían ser aplicadas a un condenado penalmente aunque se encontrara en situación de libertad condicional. Se trató del caso siguiente ${ }^{6}$ :

En las elecciones generales de 1993 la Junta Electoral Provincial de las Palmas excluyó a una persona de la proclamación de candidatos al Senado, al entender que la condena impuesta a la misma por la Sala Segunda del Tribunal Supremo (dos meses de arresto mayor, con la accesoria de suspensión de cargo público y derecho de sufragio durante dicho tiempo, así como a la pena de inhabilitación especial para cargo público y derecho de sufragio activo y pasivo durante seis años y un día) constituía causa de inelegibilidad prevista en el artículo 39 en relación con el 27 del Código Penal y el 6.2 de la LOREG.

Contra dicho Acuerdo el interesado interpuso recurso contencioso-electoral que fue desestimado. Y frente a esta Sentencia interpuso recurso de amparo electoral al entender que la causa de inelegibilidad aplicada sólo podía entrar en juego mientras el condenado se encontrara efectivamente privado de libertad pero no si estaba en libertad condicional, y que la pena principal de inhabilitación especial sólo podía aplicarse al cargo público por cuyo ejercicio fue condenado (Alcalde) ${ }^{7}$.

4 STC 45/1983.

5 STC $45 / 1983$, Fj. 2.

6 STC 166/1993.

7 El demandante de amparo consideró también vulnerados los artículo 35 y 24.1 de la Constitución, alegaciones que fueron rechazadas por el Tribunal Constitucional. 
El Tribunal Constitucional entendió que la causa de inelegibilidad que afecta a los condenados por Sentencia firme a pena privativa de libertad (art. 6.2 a) LOREG), no está en función del cumplimiento efectivo de la condena, de forma que "no depende ni puede depender de la situación personal del condenado, libertad o prisión, ya que - por otra parte — la condena condicional está concebida exclusivamente para evitar el probable efecto corruptor de la vida carcelaria en los delincuentes primarios y respecto de las penas privativas de libertad de corta duración, finalidad explícita en el momento de su implantación. Por ello, la remisión de la principal no conlleva en ningún caso la suspensión paralela de las accesorias, ${ }^{8}$.

Esto es, "la incapacidad para ser elegible se produce como consecuencia automática de la pena privativa de libertad (el arresto mayor), y sólo de ella, desconectada, pues, de su accesoria la suspensión.". Siendo aplicable las causas de inelegibilidad previstas en el art. 6.2 LOREG a toda clase de elecciones, generales o no, como pone de manifiesto su encuadramiento en el Título Primero "Disposiciones comunes para las Elecciones por sufragio universal directo", epígrafe suficientemente expresivo de su alcance general.

\subsection{Anulación de la proclamación del cargo de Senador}

Sobre esta materia el Tribunal Constitucional ha dictado tres sentencias, aunque dos de ellas se refieren al mismo caso.

En la primera de ellas, STC 21/1984, resolvió un recurso de amparo planteado frente a la Sentencia del Tribunal Supremo que declaró nulo el acuerdo de proclamación de un candidato electo al Senado efectuado por la Junta Electoral Provincial, el afectado entendía vulnerados los derechos reconocidos por los artículos 23 y 24 de la Constitución.

En relación a la vulneración del artículo 24 CE, el Tribunal Constitucional comenzó refiriéndose a las garantías de todo proceso electoral de forma que "ha de comprenderse la exigencia de un sistema electoral democrático y libre, que cuente con mecanismos que aseguren el correcto desarrollo de la elección de modo que culmine con la proclamación de los preferidos por el cuerpo electoral. En este cuadro garantizador ocupa una posición final el proceso contencioso electoral, que, obviamente, debe ajustarse tanto en su ordenación como en su desarrollo a las garantías que desde la supremacía de la CE proclama el art. 24, ${ }^{10}$.

Y continuó reiterando su doctrina respecto al art. 24 CE en el sentido de que si bien comprende "el derecho a la jurisdicción (en este caso, la contenciosa electoral) y al proceso debido, y concurriendo los presupuestos procesales, el derecho a que la pretensión contenciosa electoral se resuelva no es, obvia- 


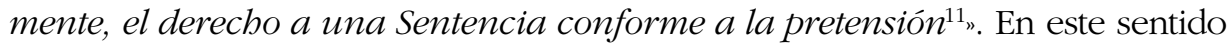
consideró que desde ningún aspecto dentro del marco de garantías que constitucionaliza el art. 24 de la CE podía ponerse tacha a la Sentencia del Tribunal Supremo.

Respecto a la vulneración del art. 23 de la CE basada en que en el escrutinio de las Secciones electorales se habían anulado votos y que el resumen general electoral reveló que hubo más papeletas que votantes, el Tribunal Constitucional consideró que antes de plantear esta denuncia no se había formulado "reclamación o protesta en el escrutinio de las Secciones o en el general, ni los intervinientes en el proceso electoral con las tareas en orden a velar por la pureza de la elección que la Ley establece, han detectado en los momentos del proceso electoral irregularidades que revistan de alguna consistencia, ${ }^{12}$.

Por otra parte, las otras dos sentencias dictadas por el Tribunal Constitucional sobre la anulación de la proclamación del cargo de Senador están relacionadas entre sí al tratarse del mismo caso. Nos referimos a las SSTC 27/1990 y 131/1990, dictadas con ocasión de sendos recursos de amparo planteados tras la celebración de las Elecciones Generales de 1989.

Se trataba de la impugnación, por parte de un candidato al Senado, del cómputo de votos realizado en una Mesa electoral. En la resolución del recurso de amparo el Alto Tribunal anuló la sentencia de la Sala Contencioso-Administrativo al entender que no se había pronunciado sobre todas las cuestiones planteadas por el recurrente durante el proceso (STC 27/1990). Posteriormente, la Sala Contencioso-Administrativo dictó nueva sentencia en la que entró a examinar lo ocurrido en el escrutinio de la Mesa objeto del contencioso, y consideró que el acta de votación no fue fiel reflejo del resultado de la votación por lo que declaró su invalidez. Ello supuso proclamar Senador electo a uno de los candidatos por una diferencia de siete votos respecto a otro candidato.

Interpuesto recurso de amparo por el candidato perjudicado por la sentencia anterior, el Tribunal Constitucional afirmó que "la Ley Electoral, en aplicación del principio de conservación de los actos, determina que la invalidez de la votación en una o varias Secciones, no comporta la nulidad de la elección cuando no altere el resultado final (art. 113.3 LOREG),"13. Sin embargo, en este caso, el Alto Tribunal entendió que la diferencia de siete votos era determinante del resultado de la elección y afectaba al resultado final.

El Tribunal Constitucional consideró que se debió ordenar efectuar una nueva convocatoria de las elecciones en la Mesa impugnada pues lo contrario supuso "vulnerar el derecho del recurrente a acceder al cargo en términos de igualdad, puesto que se le ha privado de unos votos que podrían significar su proclamación como Senador electo. Ha significado, asimismo, vulnerar el derecho a la participación en los asuntos públicos de los electores de Mamblas, 
que se han visto privados definitivamente de su voto en un supuesto no contemplado por la Ley Electoral, cuando dicho voto era relevante para el resultado de la elección, 14 .

Por todo ello, el Tribunal Constitucional anuló la proclamación como candidato electo al Senado realizada por la Sala Contencioso-Administrativo, sin que fuera necesario que dicha Sala dictara nueva sentencia, puesto que el Tribunal Constitucional suplió directamente lo que debió acordar la Sala Contenciosa como consecuencia de la nulidad declarada, esto es, ordenar la celebración de nueva votación para el Senado en la Mesa impugnada.

\subsection{Causas de inhabilitación}

Las causas de inhabilitación, que impiden a una persona ostentar un cargo público como consecuencia de una condena penal, fueron objeto de análisis por el Tribunal Constitucional en la STC 151/1999 con ocasión de un recurso de amparo interpuesto contra la Sentencia ${ }^{15}$ de la Sala Segunda del Tribunal Supremo que condenaba al demandante de amparo, por distintos delitos cometidos cuando ostentaba el cargo de Alcalde, entre otras penas, a seis años y un día de inhabilitación especial para todo cargo público electivo, accesorias de suspensión de cargo público y derecho de sufragio activo y pasivo durante el tiempo de la condena privativa de libertad.

En el momento en que el TS dictó Sentencia el demandante de amparo ostentaba la condición de Senador, por ello, éste suplicó al Tribunal Constitucional que limitara el alcance de la pena de inhabilitación especial al cargo de Alcalde, Concejal u otros análogos circunscritos al ámbito de la Administración local, sin extenderlo al cargo de Senador que ostentaba, pues de otro modo se conculcaría su derecho fundamental a conservar ese escaño ${ }^{16}$.

El Tribunal Constitucional consideró ${ }^{17}$ que pocas dudas podían albergarse "respecto de la necesidad de que los gestores públicos gocen de la confianza y el respeto de la gente. Para ello, si es exigible una cierta ejemplaridad social a quien ejerce cualquier función pública, con más intensidad debe hacerse

14 STC 131/1990, Fj. 6.

15 Y Auto de aclaración de la misma.

16 Además el demandante consideró que el TS vulneró el principio de igualdad ante la Ley pues la misma Sala, el 18 de octubre de 1993, dictó Sentencia por la que condenó a un funcionario de Correos y estableció que la pena de inhabilitación se limitaba al desempeño como empleado postal u otros empleos que estuvieran relacionados con el manejo de correspondencia, siguiendo la pauta marcada por la STC 154/1993. Argumento que fue rechazado por el TC al entender que no existía identidad de situaciones jurídicas pues "un empleado de Correos tiene una función muy definida con la cual está directa e inmediatamente relacionado el delito de infidelidad en la custodia de documentos. Tal no es el caso de quien, en cuanto Alcalde, ostenta un cargo público, obtenido tras ganar una elección popular, circunstancia suficientemente singularizada que impide el parangón de decisiones judiciales" (STC 151/1999, Fj. 2).

17 STC 151/1999, Fj. 3. 
respecto de aquellos cargos cuya función consiste precisamente, por ser representantes de los ciudadanos, en actuar de manera directa en los asuntos públicos. (...) Alcalde y Senador presentan rasgos comunes para la receptividad de los ciudadanos en cuanto a las exigencias de integridad de las personas que puedan ser los titulares de dichos cargos de representación popular (...) el representante que no ha sabido cumplir con las reglas éticas de la neutralidad y la transparencia en la gestión en el cargo de Alcalde, dificilmente puede bacerse merecedor de la confianza para otro que, como es el de Senador, participaría en manifestaciones más importantes de la voluntad popular y del ejercicio del control político al más alto nivel, ${ }^{18}$.

\subsection{Fórmulas para acatar la Constitución los Senadores electos}

En cuanto a la adquisición plena de la condición de Senador, el Tribunal Constitucional se pronunció en la STC 74/1991 al resolver el recurso de amparo interpuesto por tres Senadores electos contra la decisión del Presidente del Senado por la que se denegaba a los recurrentes la perfección de la condición de Senadores al no haber utilizado la fórmula prevista en el Reglamento de la Cámara para el acatamiento de la Constitución.

A diferencia de lo que ocurría en el supuesto de la STC 119/1990, en el que el Reglamento del Congreso de los Diputados no preveía fórmula alguna para acatar la Constitución, en el caso que ahora nos ocupa el Reglamento del Senado sí preveía una formula concreta. Por ello, el Tribunal Constitucional no consideró que se hubiera vulnerado el art. 23.2 CE en cuanto al ejercicio en condiciones de igualdad del cargo representativo, pues el Presidente del Senado se limitó a exigir el cumplimiento del requisito previamente establecido por el Reglamento de la Cámara y que fue "exigido por igual a todos los Senadores electos en esa y en las anteriores legislaturas. No se trata de una aplicación ad casum y discriminatoria, sino que, (...) se ha aplicado una norma preexistente, sin quiebra o excepciones de forma igual y sin discriminación alguna, ${ }^{19}$.

Dicho esto el Tribunal Constitucional se planteó si la aplicación por el Presidente del Senado del art. 11.3 RS, entendiendo que los recurrentes no habían acatado la Constitución al añadir a su juramento o promesa la frase "por imperativo legal, fue correcta o si, por el contrario, existió un excesivo formalismo o desproporción que vulneraba el derecho de acceso a los cargos públicos del art. 23.2 CE.

18 La Sentencia se acompaña de un Voto Particular formulado por el Magistrado D. Tomás S. Vives Antón, quien, tomando como referencia distintas Sentencias del TC, entendió que "no resulta prima facie admisible decir que todos los cargos públicos electivos sean análogos, como exige el precepto penal aplicado. (...) La afirmación contraria, que realiza la Sentencia de la que disiento, no sólo reduce materialmente el ámbito del derecho reconocido al recurrente en el art. 23.2 CE, sino que lo desconoce también formalmente, pues la previsibilidad de las medidas restrictivas de un derecho fundamental constituye una de las primeras exigencias dimanantes del mismo".

19 STC 74/1991, Fj. 3. 
El Alto Tribunal consideró que la naturaleza misma de la función representativa, con un evidente substrato democrático producto de las elecciones, refuerza la idea de interpretación flexible de los requisitos formales. El favor libertatis, que debe presidir la interpretación de los requisitos establecidos para el ejercicio de los derechos fundamentales, adquiere un particular relieve en relación con el derecho reconocido en el art. 23.2 CE. En el caso que venimos analizando, "lo decisivo es que el acatamiento a la Constitución haya sido incondicional y pleno" ${ }^{20}$.

Por ello, "cumplida la fórmula reglamentaria, el agregar a la misma la expresión "por imperativo legal" (...) debe necesariamente ser entendido como un acatamiento, o sea, como una respuesta afirmativa a la pregunta formulada por el Presidente de la Cámara (...). El añadido inicial a la fórmula de acatamiento no tiene así relevancia suficiente para vaciar de contenido el compromiso que adquirieron los recurrentes de respeto a la Constitución (...), debe ser entendido como una mera redundancia no invalidante ni limitativa del acatamiento efectivamente realizado ${ }^{21}$. Y en consecuencia procede declarar que los recurrentes han adquirido la condición plena de Senadores.

\subsection{Designación de Senadores autonómicos}

Han sido varias las ocasiones en las que el Tribunal Constitucional se ha pronunciado respecto a la designación de los Senadores autonómicos realizada por las Asambleas Legislativas autonómicas. Partiendo de la libertad que el Tribunal Constitucional reconoce desde un principio a las diferentes Comunidades Autónomas para vincular el mandato de los Senadores autonómicos bien, a la Legislatura del Senado, o bien, a la Legislatura autonómica ${ }^{22}$, el Alto Tribunal, a la hora de resolver distintos recursos de amparo, toma como punto de partida los Estatutos de Autonomía y los Reglamentos de cada Cámara concreta, aunque su Jurisprudencia sobre la materia, en algunos casos, pueda ser trasladable a otras Comunidades Autónomas.

Así en relación con la Comunidad Autónoma de Extremadura, si bien no existe precepto legal alguno que vincule el mandato de los Senadores designados por la Comunidad a la Legislatura Autonómica, su Estatuto de Autonomía establece que corresponde a la Asamblea designar de "entre sus miembros" a los Senadores correspondientes a la CCAA, lo que le llevó al Tribunal Constitucional a considerar que "terminada la representación regional, cesa el mandato senatorial, correspondiendo, en consecuencia, a dicha Asamblea en cada Legislatura proceder al nombramiento o designación de los Senadores a que se refiere el artículo 69.5 de la Constitución,"23.

20 STC 74/1991, Fj. 5.

21 STC 74/1991, Fj. 6.

22 STC 40/1981, Fj. 3 b).

23 STC 76/1989, Fj. 3. 
Mientras, en relación con el Parlamento Balear el Tribunal Constitucional afirmó que el Estatuto de Autonomía Balear "no contempla expresamente la vinculación del mandato senatorial a la Legislatura del Parlamento Balear, pero tampoco puede ser entendido (...) como explicita exclusión de toda vinculación entre el mandato del Senador designado y la legislatura autonómica. Y aunque en el artículo 181.5 del Reglamento del Parlamento Balear se reconocía implícitamente la autovinculación del Parlamento Balear "de seguir siendo representado por el mismo Senador designado al inicio de su Legislatura cuando el Senado sea disuelto antes del término de ésta", se trataba de una obligación muy débil de la que la Cámara podría liberarse si así lo deseaba pero siempre requeriría una iniciativa concreta para ello ${ }^{24}$.

Por otro lado, en relación al criterio de proporcionalidad que debe ser aplicado por las Asambleas Legislativas Autonómicas para designar a los Senadores que las representarán en la Cámara Alta, a falta de regulación expresa, el Tribunal Constitucional permite que sea la Cámara que surge tras la celebración de elecciones la que decida qué regla aplicar para ello, aunque suponga apartarse de prácticas anteriores. Considera, además, que la representación proporcional es por definición imperfecta y resulta exigible dentro de un razonable margen de flexibilidad.

En este sentido el Tribunal Constitucional considera que aunque en Legislaturas anteriores una determinada Asamblea Legislativa utilizara la regla D'Hondt para designar los Senadores autonómicos, ello no impide que en siguientes Legislaturas la nueva Cámara surgida tras la celebración de elecciones autonómicas opte por otra fórmula distinta, siempre que respete la proporcionalidad. Así ocurrió en la Asamblea de Madrid, donde la Mesa de la nueva Cámara constituida optó por aplicar el sistema de cocientes con aplicación de restos mayores y no la regla D'Hondt que venía utilizándose en Legislaturas anteriores, "lo que no puede estimarse lesivo de los derechos fundamentales del Grupo recurrente, porque, una vez elegida la regla de proporcionalidad por la Mesa, se aplica a todos los Grupos Parlamentarios por igual, circunstancia que satisface lo exigido por el artículo 23.2 de la Constitución ${ }^{25}$.

Por otra parte, "la representación proporcional es la que persigue atribuir a cada partido o a cada grupo de opinión un número de mandato en relación con su fuerza numérica. Cualesquiera que sean sus modalidades concretas, su idea fundamental es la de asegurar a cada partido o grupo de opinión una representación ajustada a su importancia real ${ }^{26}$. Por ello el criterio de proporcionalidad debe ser entendido en relación a los votos obtenidos por cada candidatura, y no en relación al grupo mayoritario frente al resto de grupos políticos $^{27}$.

24 STC 149/1990, Fj. 4.

25 STC 4/1992, Fj. 3.

26 STC 40/1981, Fj, 2.

27 STC 76/1989, Fj. 4. 


\section{Prerrogativas Parlamentarias}

El parlamentario está sujeto a un ordenamiento singular que trata de garantizar la independencia necesaria para el debido ejercicio de sus funciones. Se reconocen así, las llamadas prerrogativas de los parlamentarios como garantías funcionales que protegen no al parlamentario en cuanto tal, sino a la función parlamentaria que desempeña.

Tradicionalmente se han reconocido a los miembros de las Asambleas Legislativas las prerrogativas denominadas inviolabilidad, inmunidad y fuero especial. Sin embargo, el beneficiario último de las mismas es la Cámara, puesto que lo que se protege es la función parlamentaria en sí, y sólo indirectamente aprovechan al parlamentario individualmente considerado.

\subsection{La inviolabilidad}

En relación con la inviolabilidad parlamentaria el Tribunal Constitucional en su Sentencia 51/1985 examinó si la misma quedaba delimitada a la función parlamentaria o, si por el contrario, iba más allá de la actividad oficial dentro de las Cámaras.

El Tribunal Constitucional entendió que, si bien la inviolabilidad no decae por la extinción del mandato parlamentario, "sí requiere una correcta delimitación material y funcional. Respecto de la primera parece evidente que la garantía no ampara cualesquiera actuaciones de los parlamentarios y sí sólo sus declaraciones de juicio o de voluntad, ${ }^{28}$. En cuanto al plano funcional de la prerrogativa las "funciones" a las que hace referencia el artículo $71.1 \mathrm{CE}$ deben identificarse con las que "son propias del Diputado o Senador en tanto que sujetos portadores del órgano parlamentario, cuya autonomía, en definitiva, es la protegida a través de esta garantía individual. El Diputado o Senador ejercitaría, pues, sus funciones sólo en la medida en que participase en actos parlamentarios y en el seno de cualesquiera de las articulaciones orgánicas de las Cortes Generales, ${ }^{29}$.

En fin, el Tribunal Constitucional entendió que la inviolabilidad decae cuando los actos hayan sido realizados fuera del ejercicio de competencias y funciones que le correspondieran como parlamentario; si bien, la prerrogativa puede amparar los actos exteriores a la vida de las Cámaras, que sean reproducción literal de un acto parlamentario ${ }^{30}$.

\subsection{La inmunidad parlamentaria}

Sobre la inmunidad parlamentaria, el Tribunal Constitucional se ha pronunciado en diversas ocasiones, en algunas de las cuales ha tratado aspectos estrictamente procesales, mientras que en otras ha llegado a delimitar el ámbito 
material de la prerrogativa e, incluso, ha establecido cual debe ser el proceder de la Cámara ante la petición de un suplicatorio.

Así, en la STC 47/1982 el Tribunal Constitucional estudió si, tras la concesión del suplicatorio para proceder contra un Senador, se podía inadmitir, sin otro examen que el preliminar, un escrito de recusación contra los Magistrados de la Sala Penal del Tribunal Supremo, o si, por el contrario, debía sustanciarse la pretensión en la correspondiente pieza separada y, sobre todo, si ello formaba o no parte del derecho reconocido en el artículo 24 de la Constitución.

El Alto Tribunal señaló "que el derecho a formular la recusación comprende, en linea de principio, la necesidad de que la pretensión formulada se sustancie a través del proceso prevenido por la Ley con este fin y a que la cuestión así propuesta no sea enjuiciada por los mismos Jueces objeto de recusación, sino por aquellos otros a que la Ley defiera el examen de la cuestión. Ello no quiere decir - por supuesto - que la propuesta de recusación no pueda rechazarse de plano en el momento preliminar, pero tal decisión tiene carácter muy excepcional y sólo puede adoptarse cuando la recusación sea propuesta por quien no es parte en el proceson" 31 .

Por ello, en este caso, el Tribunal otorgó al recurrente la protección que solicitaba en orden a las garantías constitucionales que reconoce el artículo 24 de la Constitución.

También en la STC 124/2001 el Tribunal Constitucional abordó aspectos puramente procesales, en el sentido de si la práctica de pruebas realizadas a lo largo del proceso, sin la petición del suplicatorio por parte del Tribunal Supremo, vulneraba el derecho fundamental a acceder en condiciones de igualdad a los cargos y funciones públicas (art. 23.2 CE).

El Tribunal Constitucional, tras reiterar su doctrina acerca de las características de la inmunidad parlamentaria, recogida, principalmente, en sus Sentencias 90/1985, 243/1988 y 206/1992, entendió que tal "prerrogativa no impide que el Juez pueda investigar, pero veda la realización de actos que en sí mismos determinen la sujeción de un parlamentario a un procedimiento penal, ya sea mediante la expresión de un juicio formal de inculpación o a través de la práctica de otras diligencias que materialmente entrañen ese mismo significado. A lo que cabe añadir que desde el momento en que el Juez cuente con elementos suficientes para adoptar alguno de los referidos actos, está obligado a solicitar inmediatamente el suplicatorio ${ }^{32}$.

En este sentido el Alto Tribunal entendió que no es necesario solicitar el suplicatorio cuando se realicen investigaciones genéricas y no directas respecto a un parlamentario. "La exigencia de que existan indicios racionales de criminalidad o sospechas fundadas o verosimiles sobre la participación de un Diputado o Senador en los hechos objeto de investigación penal para que entre en juego la exigencia previa de autorización a la Cámara para su inculpación o procesamiento, en sí mismas consideradas, no pueden ser en modo alguno 
tildadas de contrarias o desconocedoras de la finalidad institucional a la que sirve la prerrogativa de la inmunidad. Y ello (...) no afecta al mandato representativo del parlamentario en cuanto no le imposibilita e impide el desempeño de sus funciones parlamentarias, con lo que ninguna incidencia tiene en la composición y funcionamiento de las Cámaras ${ }^{3{ }_{3}}$.

Por otro lado, es la STC 90/1985 la que marca la línea jurisprudencial que en materia de inmunidad parlamentaria seguirá el Tribunal Constitucional en adelante. En ella el Alto Tribunal analizó dos aspectos fundamentales. Primero: si el acuerdo de la Cámara por el que se deniega un suplicatorio puede ser objeto de recurso de amparo y, Segundo: la necesidad o no de que dicho acuerdo denegatorio esté motivado.

En cuanto al primer punto el Tribunal Constitucional se planteó la posibilidad de que el Senado, aun no siendo órgano jurisdiccional, violara el contenido del derecho fundamental a la tutela judicial efectiva del artículo 24.1 de la Constitución. Pues la posibilidad de conceder o denegar suplicatorios en que la institución de la inmunidad se concreta, afecta a la disponibilidad del proceso penal y, por tanto, la decisión de la Cámara "queda así vinculada a la función de impartir justicia y en tal medida le son aplicables los parámetros del articulo 24.1 de la $C E^{34}$. Con ello el Tribunal Constitucional abrió la posibilidad de que un acto interno de las Cámaras, como es la denegación de un suplicatorio, sea revisable en sede constitucional a través del recurso de amparo.

En relación al segundo punto el Tribunal Constitucional exigió que la respuesta de la Cámara a una petición de suplicatorio se hiciera de forma expresa y motivada ${ }^{35}$, pues entendió que la denegación de un suplicatorio ha de "considerarse correcta, desde la perspectiva del artículo $24.1 \mathrm{CE}$, únicamente en el caso que dicha denegación sea conforme a la finalidad que la institución de la inmunidad parlamentaria persigue y en la que la posibilidad de denegación se fundamenta, ${ }^{36}$.

En el caso que nos ocupa, el acuerdo adoptado por el Pleno del Senado por el que se denegó la autorización para procesar, aparecía desprovisto de motivación alguna, y tampoco ésta podía deducirse de las alegaciones formuladas en el procedimiento de amparo por la representación de las Cortes Generales. Esto, unido a las propias circunstancias de la querella ocasionada por un escrito de carácter estrictamente literario del que era autor el Senador en cuestión, que además accedió a la Cámara Alta con posterioridad, no concurriendo ningún elemento que permitiera apreciar, en la interposición de la querella, la existencia de móviles o intencionalidades políticas, le llevó al Tribunal Constitucional a declarar que se había producido la violación del derecho

33 STC 124/2001, Fj. 5.

34 STC 90/1985, Fj. 6.

35 A este respecto conviene recordar que los Reglamentos del Senado y del Congreso de los Diputados prevén la posibilidad del silencio negativo como respuesta a un suplicatorio (art. 22.5 RS y 14.2 RCD).

36 STC 90/1985, Fj. 6. 
fundamental reconocido en el artículo 24.1 CE, al considerar que la denegación del suplicatorio, acordada por el Senado aparecía del todo desvinculada de la finalidad que persigue la inmunidad parlamentaria ${ }^{37}$.

A su vez, el Tribunal Constitucional en la STC 206/1992 dió un paso más respecto a la sentencia anterior, pues exigió que la denegación del suplicatorio no sólo se realizara de forma motivada sino que dicha motivación debía ser acorde con la finalidad que persigue la inmunidad parlamentaria.

En este caso, una vez revisado el Acuerdo del Senado por el que se denegaba un suplicatorio, el Tribunal Constitucional coincidía con el Ministerio Fiscal, al apreciar que saltaba a la vista la omisión en el mismo de cualquier incidencia de la concesión o no del suplicatorio en la composición de la Cámara o a su normal funcionamiento. No había nada que pudiera considerarse relevante para el sentido constitucionalmente perseguido a través de la prerrogativa de la inmunidad parlamentaria. En base a ello, el Tribunal Constitucional no dudó en otorgar el amparo solicitado ${ }^{38}$, al entender insuficiente la argumentación jurídica del acuerdo del Pleno del Senado, vulnerando, así "el derecho a la tutela efectiva de los Jueces y Tribunales reconocido en el artículo 24.2 CE al haber determinado, de forma contraria a Derecho, el sobreseimiento de las querellas formuladas por los recurrentes, 39 .

Finalmente, el ámbito material de la prerrogativa quedó definido en la STC 243/1988 ${ }^{40}$, en la que el Tribunal Constitucional examinó si la LO 3/1985, por la que se ampliaba el requisito del suplicatorio a los procedimientos civiles, constituía una limitación del derecho a la tutela judicial reconocido por la Constitución.

Afirmaba el Alto Tribunal que este derecho garantiza a todas las personas el acceso a los procesos legalmente previstos y la obtención dentro de ellos, de una resolución sobre el fondo, siempre que la prestación jurisdiccional se reclame cumpliendo los requisitos y presupuestos procesales a los que la Ley, con generalidad y sin infringir la Constitución, condicione la viabilidad de la pretensión.

La LO 3/1985 introduce un requisito excepcional y privilegiado al suponer que no cabe dar curso a una demanda civil interpuesta contra un parlamentario, sin antes haber obtenido la autorización para proceder de la Cámara respectiva. Tal requisito excepcional sólo será conforme si cuenta con un fundamento constitucional positivo, pues sólo en la Constitución se podrá encontrar la razón jurídica de una restricción semejante a la obtención de la tutela judi-

37 STC 90/1985, Fj. 7.

38 La Sentencia se acompaña de tres votos particulares suscritos por cuatro Magistrados.

39 STC 206/1992, Fj. 5.

40 A raíz de la STC 243/1988 de 19 de diciembre, la Sala Primera del Tribunal Constitucional decidió hacer uso de la facultad que le otorgaba el artículo 55.2 LOTC y elevó al Pleno una cuestión de inconstitucionalidad a fin de determinar la conformidad o disconformidad constitucional de lo dispuesto en el segundo inciso del artículo 2.2 de la L.O. 1/1982, introducido por la L.O. 3/1985. La autocuestión de inconstitucionalidad fue resuelta por el Pleno en la STC 9/1990, de 18 de enero, que declaró la inconstitucionalidad de la L.O. 3/1985. 
cial, la cual hay que buscarla en el artículo 71 de la Constitución (STC 243/1988, Fj. 4).

En este sentido el Tribunal Constitucional entendió que "La inmunidad parlamentaria se manifiesta inapropiada para impedir el curso de una demanda civil interpuesta contra un parlamentario, pues el sentido propio de las palabras empleadas por el artículo 71 de la Constitución, los antecedentes históricos y legislativos de esa prerrogativa de los miembros de las Cámaras y la razón misma de la institución excluyen, con absoluta claridad, que su protección se extienda a procesos que no sean penales, es decir, que no entrañen la eventualidad de que sean utilizados con la intención de perturbar el funcionamiento de la Cámara o alterar su composición, mediante la posible privación de libertad del parlamentario "41.

Por ello, la previa autorización que exige el artículo 71 de la Constitución para inculpar o procesar a un parlamentario, no puede exigirse para la admisión, tramitación y resolución de demandas civiles que en nada pueden afectar a su libertad personal y, en consecuencia, la extensión al ámbito civil de dicha garantía procesal resulta constitucionalmente ilegítima. Ilegitimidad que no puede eludirse trasladando el requisito excepcional de la previa autorización parlamentaria al ámbito de la inviolabilidad, pues tal desnaturalización de este privilegio no viene consentida por la Constitución ${ }^{42}$.

\subsection{El fuero especial}

Respecto al fuero especial en la STC 51/1985 el Tribunal Constitucional reiteró su doctrina en relación con esta prerrogativa y el derecho a la doble instancia judicial recogida en la STC 42/1982. Así, el Alto Tribunal afirmó que "por mor de lo dispuesto en el artículo 14, núm. 5, del Pacto Internacional de Derechos Civiles y Políticos ratificado por España, el derecho al doble grado de jurisdicción en materia penal es una de las garantías a que la Constitución se refiere al emplear la cláusula "todas". Ahora bien, el articulo 14 del Pacto Internacional, "aunque es derecho interno, no es bastante para crear por sí mismo recursos inexistentes, ${ }^{43}$.

"Además, es de tener en cuenta que, en supuestos como el que nos ocupa, la necesidad de que en las causas contra Diputados y Senadores sea competente la Sala de lo Penal del Tribunal Supremo, que es el "órgano jurisdiccional superior en todos los órdenes, salvo lo dispuesto en materia de garantias constitucionales" (art. 123.1 de la Constitución), está impuesta por el artículo 71.3 de la Constitución. Determinadas personas gozan, ex Constitutione, en atención a su cargo, de una especial protección que contrarresta la imposibilidad de acudir a una instancia superior, pudiendo afirmarse que esas parti- 
culares garantías que acompañan a Senadores y Diputados disculpan la falta de un segundo grado jurisdiccional, por ellas mismas y porque el órgano encargado de conocer en las causas en que puedan hallarse implicados es el superior en la vía judicial ordinaria, ${ }^{44}$.

\section{ORGANIZACIÓN INTERNA Y FUNCIONAMIENTO DEL SENADO}

El Tribunal Constitucional no ha tenido demasiadas ocasiones de pronunciarse sobre la organización interna y el funcionamiento del Senado. Únicamente en tres sentencias el Alto Tribunal resuelve cuestiones relativas a la organización de esta Cámara. Una de ellas se refiere a las competencias de la Mesa, las otras dos, a la regulación del Estatuto del Personal al servicio de las Cortes Generales.

\section{Sobre las Competencias de la Mesa. La Admisión de mociones NO LEGISLATIVAS}

La única sentencia relativa a los órganos internos del Senado y sus competencias es la STC 205/90, de 13 de diciembre, por la que el Tribunal resolvió un recurso de amparo presentado por el Grupo Parlamentario de CiU contra el acuerdo de la Mesa de no admitir a trámite una moción sobre el uso de lenguas oficiales. Se trata de una decisión relevante, en primer lugar, porque contiene uno de los pronunciamientos más completos acerca de las funciones de calificación y admisión de documentos que corresponden a las Mesas como órganos rectores de las Cámaras, y, en segundo lugar, porque dejó abierta la posibilidad de que en el Senado se discutiera sobre el uso de lenguas oficiales, como luego se hizo.

Los recurrentes consideraron que la Mesa se había excedido en el ejercicio de la función calificadora y de admisión de documentos e iniciativas que le atribuye el art. 36.1.c) del Reglamento del Senado. Para delimitar el alcance de esta función el Tribunal analizó los correspondientes preceptos del Reglamento y dedujo, primero, que la regla general es la prevista en el art. 36.1.c) RS, de acuerdo con el cual corresponde a la Mesa calificar los escritos y documentos, así como decidir sobre su admisibilidad y tramitación, y, segundo, que frente a esta regla general el art. 175.1 RS establece una regla especial sobre la admisibilidad de mociones no legislativas, de acuerdo con la cual sólo podrían rechazarse las mociones ya votadas por el Senado en el mismo período de sesiones ${ }^{45}$.

44 STC 51/1985, Fj. 3.

45 STC 205/1990, Fj. 6. El art. 174.d) del Reglamento del Senado establece que las mociones podrán presentarse para que la Cámara delibere y se pronuncie sobre un texto de carácter no legislativo. De acuerdo con el art. 175.1, dichas mociones se formularán mediante escrito dirigido a la Mesa a efectos de su inclusión en el orden del día y podrá rechazarse la inclusión de mociones idénticas a las ya votadas en ese período de sesiones. 
A juicio del Tribunal, esa regla especial, sin embargo, "no impide, obviamente, un juicio de admisión a cargo de la Mesa sobre el cumplimiento de los requisitos formales reglamentariamente establecidos e, incluso, una verificación liminar de la conformidad a derecho de la pretensión deducida, junto a un juicio de calificación sobre la idoneidad o procedencia del procedimiento parlamentario elegido. Pero la intervención de la Mesa en este concreto procedimiento no puede prejuzgar el éxito o la oportunidad política de la moción, sino que antes bien debe limitarse a controlar su regularidad jurídica y viabilidad procedimental; de tal forma que sólo cuando el contenido de la moción sea inequívocamente extraño a las finalidades establecidas para estas mociones en el art. 174 o manifiestamente contrario a derecho o inconstitucional, el Reglamento permite acordar la inadmisión por la Mesa, pues del contenido de la pretensión deducida debe ocuparse el Pleno con independencia del sentido en que lo haga ${ }^{46}$.

Así pues, dado que "las potestades de calificación y admisión de que dispone con carácter general la Mesa deben ser puestas en conexión con el procedimiento parlamentario del que forman parte", en el caso de mociones no legislativas, es el propio Reglamento el que establece que sólo pueden rechazarse mociones idénticas a las ya votadas; de acuerdo con ello, "las potestades de calificación de la Mesa deben ser interpretadas restrictivamente, sin usurpar funciones de deliberación y discusión, que, si se pone en conexión el art. 174.d con el art. 175.1, sólo corresponden al Pleno ${ }^{47}$.

En el caso concreto que ocupó al Tribunal, la moción se refería al uso indistinto en todas las actividades parlamentarias de la Cámara de cualquiera de las lenguas oficiales. La Mesa consideró que el contenido de la moción era contrario a la Constitución y decidió no admitirla a trámite. A juicio del Tribunal, "dicha moción, ni presentaba irregularidades formales, ni en modo alguno puede estimarse que en aquel momento de la tramitación su contenido resultase manifiestamente contrario a derecho por inconstitucional. Entendió el Tribunal que, dado que la ordenación del pluralismo lingüístico presenta una notable complejidad, es difícil afirmar que la moción inadmitida resulta inequívocamente inconstitucional en un juicio liminar, como es el que corresponde efectuar a la Mesa, y concluyó que "la inconstitucionalidad de la moción controvertida no resultaba manifiesta e inequívoca y que, en consecuencia, la Mesa no debió acordar su inadmisión a trámite, burtando juicios de oportunidad política que, conforme al procedimiento recogido en los arts. 174 y ss. del Reglamento del Senado, sólo corresponderían al Pleno" ${ }^{48}$.

46 STC 205/1990, Fj. 6.

47 STC 205/1990, Fj. 6.

48 STC 205/1990, Fj. 7. La sentencia se dictó una vez concluida la legislatura, por lo que sus efectos fueron fundamentalmente declarativos, ya que no podía restablecerse el derecho vulnerado. Sin embargo esta sentencia dejó abierta la posibilidad de que volviese a discutirse el uso de lenguas oficiales en el Senado y en 1994 se reformase el Reglamento de la Cámara para regular el uso en determinados supuestos de las diferentes lenguas oficiales. 


\section{La Regulación del Estatuto del Personal de las Cortes Generales}

En relación con el Estatuto del Personal al servicio de las Cámaras parlamentarias, cuya aprobación corresponde a las Mesas del Congreso y del Senado, se han planteado dos recursos de amparo que permitieron al Tribunal Constitucional pronunciarse sobre las dos siguientes cuestiones.

\subsection{Naturaleza jurídica del Estatuto del Personal}

El primer recurso de amparo en esta materia se presentó contra un acuerdo de las Mesas del Congreso y del Senado por el que se modificaba el Estatuto del Personal, en concreto, el régimen de preparación de opositores al Cuerpo de funcionarios de las Cortes por parte de funcionarios en activo. Pero el debate que generó el recurso se centró, no tanto en esa cuestión de fondo, como en una concreta cuestión de forma. Los recurrentes consideraban que el acuerdo recurrido no es una norma con valor de ley, sino «una norma reglamentaria, menor o secundaria, por relación a los Reglamentos de la Cámara", por lo que su enjuiciamiento corresponde a la jurisdicción contenciosa $\mathrm{y}$, frente a una eventual falta de tutela judicial efectiva, puede recurrirse en vía de amparo. Las Cortes Generales, por el contrario, entendían que el Estatuto del Personal, y el acuerdo que lo modifica, es una decisión o acto con valor de ley que, por ello, no puede ser objeto de recurso de amparo ${ }^{49}$.

En la Sentencia 139/88, por la que se resuelve este recurso, el Tribunal determinó cuál es la naturaleza jurídica del Estatuto del Personal, afirmando que "la Constitución, en su art. 72.1 establece una reserva formal y material a favor del Estatuto del Personal de las Cortes Generales, de manera que este Estatuto aparece como una norma directamente vinculada a la Constitución, es decir, como una norma primaria - o acto normativo primario- que, por ello mismo, determina que la regulación a él encomendada quede fuera del alcance de cualquier otra norma jurídica. Así pues, el Estatuto del Personal, por imperativo constitucional, goza de una efectiva fuerza de ley, al menos en su dimensión pasiva. Con esto entendió el Tribunal que el Estatuto del Personal (y en principio también el acuerdo que lo modifica) no es equiparable a las normas reglamentarias "ya que a diferencia de éstas, aquel no se halla subordinado a la ley, sino directamente incardinado y vinculado a la Constitución. No se trata de una disposición de categoría inferior a la ley, sino, antes bien, de una norma que, de acuerdo con la reserva constitucional establecida, goza de fuerza de ley, y que, asimismo, por proceder del Poder legislativo, posee valor de ley." 50

Desde el punto de vista procesal, a pesar de que el art. 27.2 de la LOTC no menciona expresamente el Estatuto del Personal, el Tribunal Constitucional

49 STC 139/1988, Fj. 2.

50 Ibíd. 
consideró que entre los supuestos susceptibles de declaración de inconstitucionalidad se incluyen los "actos del Estado con fuerza de ley, ${ }^{51}$, categoría ésta en la que, a los efectos señalados, puede subsumirse sin dificultad alguna el referido Estatuto. Así pues concluyó el Tribunal que "la Constitución, dada la reserva formal y material que a favor del Estatuto del Personal de las Cortes establece, da plena cobertura a la calificación de dicha norma, y de los acuerdos que la modifiquen, como disposición con valor y fuerza de ley no susceptible en sí misma de impugnarse, sino a través del recurso de inconstitucionalidad, ${ }^{52}$.

\subsection{Alcance de la autonomía para la regulación del Estatuto del Personal}

El segundo recurso de amparo relativo al Estatuto del Personal de las Cortes Generales se presentó contra la Resolución de los Presidentes del Congreso y del Senado por la que, de acuerdo con el citado Estatuto, se dictaron Normas reguladoras de las elecciones a la Junta de Personal de las Cortes. Los recurrentes, una organización sindical ya inscrita en el correspondiente registro, consideraron contraria a la libertad sindical la obligación de inscribirse nuevamente en un registro creado al efecto en las Cortes para poder concurrir a las elecciones, tal y como exigían las Normas recurridas.

Antes de analizar si se había lesionado la libertad sindical de los recurrentes el Tribunal tuvo que determinar el alcance de la autonomía normativa de las Cámaras en relación con el Estatuto de su Personal. En este sentido, afirmó que "la autonomia organizativa de las Cámaras (art. 72.1 CE) no cobija una potestad normadora de carácter genérico", sino que "como prerrogativa constitucional al servicio de su independencia frente a eventuales injerencias de otros poderes públicos, dicha potestad normativa interna se proyecta exclusivamente sobre el ámbito material que determina el propio art. 72. CE. De acuerdo con dicho artículo, corresponde a las Cámaras aprobar de común acuerdo el Estatuto del Personal de las Cortes "entre cuyos contenidos pueden figurar disposiciones relativas a las elecciones sindicales y a los órganos de representación de su personal que, dentro del respeto a la Constitución y, en principio, también a la Ley Orgánica de Libertad Sindical —en tanto que norma de desarrollo directo del derecho fundamental a la libertad sindical-, introduzcan ciertas variaciones o adaptaciones normativas en atención a las peculiaridades estatutarias del personal al servicio de las Cortes Generales, 53 .

En relación con las disposiciones concretas recurridas, el Tribunal consideró que, en ejercicio de su autonomía organizativa, las Cortes Generales pueden constituir un registro propio de organizaciones sindicales y facilitar así el reconocimiento de la personalidad jurídica y de la capacidad de obrar de los

51 Art. 27.2.b) LOTC y art. 161.1.d) CE.

52 STC 139/1988, Fj. 2.

53 STC 121/1997, Fj. 10. 
sindicatos que vayan a desarrollar su actividad en las Cortes (especialmente cuando el art. 4 de la Ley Orgánica de Libertad Sindical únicamente se refiere a "la oficina pública establecida al efecto. Pero las disposiciones recurridas establecían también que la inscripción en dicho registro era obligatoria para concurrir a las elecciones sindicales, lo cual constituye "una alteración del sistema de reconocimiento de personalidad jurídica de los sindicatos, elemento de tal trascendencia en el régimen jurídico de éstos que "requiere una justificación constitucional específica, ${ }^{54}$. Sin embargo, comprobó el Tribunal que en las alegaciones de las Cortes no se justificaba la razón de esta medida, "ni, prima facie, se aprecia conexión alguna entre la obligación impuesta a los sindicatos de tener que volver a constituirse nuevamente ante el Registro de las Cortes Generales y la necesidad de garantizar su autonomía e independencia como órgano constitucional, que es la razón de ser de la autonomía organizativa de las Cortes Generales 55 .

No obstante lo anterior, el Tribunal propuso una interpretación de dichas disposiciones, de tal modo que éstas, así entendidas, no fuesen contrarias a la libertad sindical. "El art. 23 del Estatuto del Personal de las Cortes Generales puede ser interpretado sin dificultad en el sentido de que la inscripción en el Registro que en él se establece carece de carácter constitutivo en el supuesto de aquellos sindicatos que, como es el caso del recurrente, decidiesen desplegar su actuación en el ámbito de las Cortes Generales y ya tuviesen reconocida personalidad con arreglo al sistema general previsto en la Ley Orgánica de Libertad Sindical, 56 .

\section{FUNCIONES Y COMPETENCIAS DEL SENADO}

La Constitución establece las competencias que corresponden a cada una de las Cámaras en el ejercicio de las funciones atribuidas a las Cortes Generales y coloca al Senado en una posición claramente secundaria respecto del Congreso. Debido a esa diferencia en lo que a competencias concretas se refiere, podríamos decir que las sentencias en las que el Tribunal Constitucional se ha pronunciado sobre las competencias atribuidas al Senado contienen la verdadera "jurisprudencia" sobre el Senado, porque se refieren específicamente a la Cámara Alta y lo que en ellas se afirma no es predicable de otras Cámaras legislativas.

Sin ser numerosas, las sentencias en las que el Tribunal Constitucional se ha pronunciado sobre las funciones y competencias del Senado revelan una in-

54 El Tribunal recordó que la libertad sindical comprende el derecho a fundar sindicatos sin autorización previa dentro del respeto a la Constitución y a la Ley, y que la obligación de inscribirse en un registro se exige únicamente para adquirir personalidad jurídica y capacidad de obrar (STC 121/1997, Fj. 9).

55 Ibíd.

56 STC 121/1997, Fj. 11. 
terpretación clara del Tribunal al respecto, una interpretación muy pegada a la letra de la Constitución (y de los Reglamentos parlamentarios) y que, por lo tanto, confirma esa posición secundaria del Senado respecto al Congreso que caracteriza a nuestro "bicameralismo imperfecto".

\section{EJERCiCiO DE la POTESTAD LeGisLativa}

\subsection{Participación en el procedimiento legislativo}

\subsubsection{La presentación de enmiendas}

En las SSTC 99/87 y 194/2000 el Tribunal Constitucional se pronunció sobre el alcance de la facultad del Senado para presentar enmiendas a textos aprobados por el Congreso. En ambos casos se trataba de enmiendas introducidas por el Senado cuyo contenido era más o menos diferente del contenido de la ley que se tramitaba ${ }^{57}$; y en ambos casos los recurrentes consideraron que, dado que se trataba de disposiciones ajenas a la ley, se debería haber presentado una proposición de ley autónoma, en lugar de haberlas incluido como enmiendas a una ley de contenido diferente, además de que, actuando así, se habían sustraído dichas disposiciones del debate y la facultad de enmienda del Congreso ${ }^{58}$.

De acuerdo con la interpretación del Tribunal manifestada en esas dos sentencias, de la letra de la Constitución y de los Reglamentos parlamentarios se deduce que el Senado no tiene límite material alguno, salvo los expresamente establecidos en la Constitución, para introducir enmiendas en los textos aprobados por el Congreso. Esta interpretación ha sido objeto de ciertas críticas por parte de quienes consideran que, por seguridad jurídica, entre otras razones, podrían exigirse ciertos requisitos de homogeneidad y congruencia a las enmiendas del Senado, como el Tribunal Constitucional ha hecho ya en casos similares pero relativos a otras asambleas legislativas ${ }^{59}$.

57 En la STC 99/1987 se resuelve un recurso de inconstitucionalidad presentado contra ciertas disposiciones adicionales a la Ley de medidas para la reforma de la función pública, introducidas en el Senado, y relativas a la clasificación de los cuerpos de funcionarios, a los cuerpos de funcionarios docentes y a los cuerpos de funcionarios de la Seguridad Social. En la STC 194/2000 se resuelve un recurso de inconstitucionalidad presentado contra una disposición adicional a la Ley de tasas y precios públicos, introducida en el Senado, y relativa a la comprobación de los valores declarados y de relevancia para el Impuesto del Patrimonio, el Impuesto de Sociedad y el Impuesto de la Renta.

58 Posteriormente se han presentado otros recursos de inconstitucionalidad por el mismo motivo: el recurso 390/99 contra la Ley de acompañamiento 50/98, con motivo de las compensaciones a las compañías eléctricas por los costes de transición; y el recurso 1827/2000 contra la Ley de acompañamiento 55/99, respecto a las fundaciones sanitarias.

59 Vid. la STC 23/1990, el ATC 275/1993 y el ATC 118/1999. Los comentarios en L. de la Peña Rodríguez, Derecho parlamentario español y Tribunal Constitucional, op. cit., p. 367 y ss.; A. Arce Janariz, "El derecho de enmienda visto por el Tribunal Constitucional", REDC n. ${ }^{\circ} 41,1994$, p. 151 y ss.; y El Parlamento en los Tribunales, op. cit., p. 116 y ss. 
a) En el primer caso el Tribunal comenzó determinando el parámetro de constitucionalidad aplicable, para lo cual tuvo que aclarar una cuestión que se había planteado ya anteriormente y a la que no se había dado una respuesta definitiva: en qué medida los Reglamentos parlamentarios pueden ser parámetro de constitucionalidad. El Tribunal explicó que, aunque los Reglamentos no se mencionen en el art. 28.1 de la LOTC, en el que se define el bloque de la constitucionalidad, "tanto por la invulnerabilidad de tales reglas de procedimiento frente a la acción del legislador como, sobre todo, por el carácter instrumental que esas reglas tienen respecto de uno de los valores superiores de nuestro ordenamiento, el del pluralismo político (art. 1.1 C.E.), la inobservancia de los preceptos que regulan el procedimiento legislativo podría viciar de inconstitucionalidad la ley cuando esa inobservancia altere de modo sustancial el proceso de formación de voluntad en el seno de las Cámaras, ${ }^{60}$.

Así, consideró el Tribunal que para desechar el argumento de los recurrentes bastaba comprobar que no ofrecían en su apoyo precepto reglamentario o constitucional alguno que hubiese sido quebrantado, "pues, efectivamente, no existe ni en la Constitución ni en los reglamentos de ambas Cámaras norma alguna que establezca una delimitación material entre enmienda y proposición de Ley. Ni por su objeto, ni por su contenido, hay límite alguno a la facultad que los miembros de las Cámaras tienen para presentar enmiendas, exceptuados los que, tanto para las enmiendas como para las proposiciones de Ley, fijan los arts. 84 y 134.6 de la Constitución para asegurar un ámbito de acción propia al Gobierno. Al aceptar como enmienda lo que un Grupo Parlamentario presentó como tal no ha habido, en consecuencia, ni podría haber, infracción reglamentaria alguna y por tanto tampoco inconstitucionalidad ${ }^{61}$.

Por otro lado, respecto de la facultad de la Mesa de calificar (rectificar) con arreglo al Reglamento los documentos parlamentarios, a la que los recurrentes también habían apelado, entendió el Tribunal que la calificación de un escrito que haya hecho su autor sólo puede rectificarla la Mesa cuando efectivamente pueda apoyar esta rectificación en algún precepto reglamentario, cosa que no sucedía en este caso ${ }^{62}$.

b) En la segunda sentencia el Tribunal Constitucional confirmó la interpretación realizada en la sentencia anterior. El Alto Tribunal admitió a los recurrentes que su tesis, "según la cual las enmiendas de adición formuladas en el Senado que supongan una innovación importante deben seguir el cauce legal correspondiente a los proyectos de ley, puede invocar en su favor razones de corrección técnica y buena ordenación del procedimiento legislativo e incluso puede resultar más acorde con la posición constitucional atribuida al Senado en nuestro ordenamiento jurídico, pero no se deduce necesariamente del bloque de la constitucionalidad. Remitiéndose a la sentencia anterior recordó

60 STC 99/1987, Fj. 1.

61 Ibíd.

62 Ibíd. 
que en ella ya se había reconocido que la facultad de enmendar del Senado la establecen expresamente la Constitución y el Reglamento del Senado, normas que no recogen límites a esta facultad, y en las que tampoco se establece una delimitación material entre enmienda y proposición de Ley ${ }^{63}$.

En este caso el Tribunal se pronunció también sobre el argumento de los recurrentes de acuerdo con el cual el procedimiento empleado había restringido las facultades del Congreso de los Diputados, limitándose a afirmar que dicho procedimiento se había ajustado a lo establecido en la Constitución y los Reglamentos parlamentarios, además de que, en este caso concreto, el Senado había enviado mensaje motivado al Congreso sobre la enmienda introducida, mensaje que fue objeto de debate y votación en el mismo ${ }^{64}$.

\subsubsection{Rechazo a un texto aprobado por el Congreso sin presentar enmiendas ni veto}

La jurisprudencia del Tribunal Constitucional sobre la participación del Senado en el procedimiento legislativo se completa con una importante sentencia, la STC 97/2002, en la que el Tribunal se pronuncia sobre la diferente posición del Congreso y el Senado en dicho procedimiento, y sobre los dos únicos modos en que el Senado puede manifestar su disconformidad con un texto aprobado por el Congreso.

La sentencia resuelve un recurso de inconstitucionalidad en el que se alegaba un vicio "in procedendo", que se habría producido porque en el Congreso, tras recibir del Senado el rechazo a una proposición de ley, pero no un veto ni enmiendas a la misma, no se comunicó dicho rechazo al Pleno de la Cámara para que decidiese, sino que la Mesa dio traslado de la proposición a la Presidencia para su sanción real ${ }^{65}$.

Los recurrentes consideraron que no se tuvo en cuenta la voluntad del Senado, que había expresado su rechazo a la proposición de ley. El Senado, por su parte, alegó que, dada la capacidad colegisladora del Senado establecida en el art. 66.2 CE y la importancia del procedimiento de elaboración de las leyes, no cabe un entendimiento cerrado y exhaustivo del art. 90.2 CE, y que el debate del Pleno del Senado no se desarrolla sólo sobre enmiendas y vetos, sino también sobre otros objetos distintos, lo que implica que el resultado puede ser ni la aprobación, ni el veto, ni la introducción de enmiendas ${ }^{66}$.

63 STC 194/2000, Fj. 3.

64 Ibíd.

65 La situación trae causa de que en el Senado un grupo parlamentario presentó una propuesta de veto; la Comisión correspondiente, dejando la votación del veto para el Pleno, aprobó el informe de la Ponencia en el que no se propusieron enmiendas; en el Pleno se rechazó la propuesta de veto, y, al votar el dictamen de la Comisión, tampoco hubo votos suficientes para aprobarlo, por lo que el Presidente declaró rechazado el texto.

66 STC 97/2002, antecedentes 3.A y 13. 
El Tribunal comenzó su argumentación recordando lo afirmado en la STC 99/1987 sobre la inconstitucionalidad de la ley por vicios de procedimiento y el parámetro para determinarla, esto es, que las normas constitucionales y parlamentarias que regulan la elaboración de las leyes tienen carácter instrumental respecto del valor superior del pluralismo político, de modo que la inobservancia de dichas normas "podría viciar de inconstitucionalidad la ley cuando esa inobservancia altere de modo sustancial el proceso de formación de la voluntad en el seno de las Cámaras". De acuerdo con esto, es preciso examinar si se ha producido o no vulneración de la normativa reguladora del procedimiento legislativo y, en su caso, valorar si la vulneración tuvo relevancia para la formación de la voluntad legisladora ${ }^{67}$.

El Tribunal analizó la normativa reguladora del procedimiento legislativo, advirtiendo que la Constitución ha regulado con detalle dicho procedimiento (arts. 87 a $91 \mathrm{CE}$ ) y que, "frente al sistema tradicional de nuestro bicameralismo — Comisión mixta de diputados y senadores- el art. 90.2 atribuye un destacado protagonismo al Congreso, que tiene la decisión final sobre las discrepancias del Senado respecto a los textos remitidos por aquél... (El art. 90), en el que se concentra la regulación de la tramitación en el Senado de los proyectos de ley, se configura como uno de los varios preceptos constitucionales en los que se plasma la diferente posición que ocupan el Congreso y el Senado en el procedimiento legislativo ordinario, así como de las relaciones entre una y otra Cámara en el ejercicio de la potestad legislativa que el art. 66.2 CE residencia en las Cortes Generales, todo lo cual responde, en definitiva, a la característica configuración del modelo bicameral adoptado por nuestra Constitución ${ }^{68}$.

En respuesta a las alegaciones de los recurrentes y del Senado, que razonaban desde el art. 66.2 CE y desde la capacidad colegisladora que este artículo atribuye al Senado, el Tribunal afirmó que aunque la relación entre los arts. 66 y 90 no es de jerarquía, como argumenta el Senado, lo cierto es que el primero es una disposición general y el segundo una disposición especial. "Mientras que el art. 66.2 .. atribuye globalmente la potestad legislativa del Estado a las Cortes Generales (Congreso y Senado), el art. 90.2... concreta las funciones que dentro del procedimiento legislativo, en lo que abora importa, corresponden específicamente a cada una de las Cámaras: por una parte, regula la actuación que al Senado corresponde en el curso de dicho procedimiento..., y, por otra, especifica los concretos supuestos de discrepancia del Senado que dan lugar a una ulterior lectura en el Congreso, supuestos éstos que son sólo dos (oponer su veto o introducir enmiendas)... En definitiva, es el art. 90.2 el que concreta el sentido de la capacidad colegisladora del Senado prevista en el art. 66.2,69.

67 STC 97/2002, Fj. 2.

68 STC $97 / 2002$, Fj. 4, citando la STC 234/2000, Fj. 8.

69 STC 97/2002, Fj. 4, citando la STC 234/2000, Fj. 13, que analizamos en el siguiente apartado ("la potestad legislativa que residencia en las Cortes Generales el art. 66.2 CE se ejerce por cada una de las Cámaras que la integran, en la forma y con la extensión que el propio texto determina...y, en concreto, por lo que se refiere a la tramitación en el Senado de los proyectos de ley, en los términos en los que establece su art. 90"). 
Respecto al procedimiento que diseña el art. $90 \mathrm{CE}$, el Tribunal señaló que "uno de los fines a que responde el art. $90 \mathrm{CE}$ es precisamente el logro de una cierta celeridad en la tramitación senatorial...; propósito de celeridad este en cuya linea se inscribe la limitación de los supuestos de regreso del texto al Congreso, lo que hace difícil una interpretación extensiva de aquellos. Así concluyó el Tribunal que, conforme al art. $90 \mathrm{CE}$, las únicas discrepancias del Senado que pueden provocar una nueva lectura en el Congreso son la oposición de veto o la presentación de enmiendas ${ }^{70}$.

En cuanto a los Reglamentos parlamentarios, la conclusión anterior "impide cualquier interpretación del Reglamento del Senado que pretenda ampliar los supuestos de discrepancia de esta Cámara con el Congreso que han de dar lugar a una nueva consideración del texto en éste, dado que, en primer lugar, y sobre todo, la autonomía parlamentaria está subordinada a la Constitución ${ }^{71}$. No obstante, como el Tribunal comprobó, el Reglamento únicamente prevé las dos discrepancias del Senado ya señaladas (veto o enmiendas) ${ }^{72}$.

Por otro lado, el Tribunal respondió a la interpretación del Senado de acuerdo con la cual el rechazo expresado por el Pleno de la Cámara implicaba una enmienda de totalidad, lo que debía dar lugar al reenvío del texto al Congreso para su consideración en Pleno. El Tribunal reconoció que "ciertamente el veto integra un rechazo frontal y global al proyecto o proposición remitidos por el Congreso, es decir, una enmienda a la totalidad..., pero (ese veto) está sometido al régimen jurídico expresamente delineado en ese precepto (art. 90.2 CE), esto es, aprobación por mayoría absoluta.

Remitiéndose al debate constituyente, el Tribunal recordó que el Anteproyecto constitucional no establecía una diferenciación de veto y enmiendas en el ámbito senatorial, lo que dio lugar a que se formularan enmiendas y la Comisión del Congreso diese una redacción definitiva dirigida a deslindar los supuestos de veto y enmiendas, "exigiendo para aquél la mayoría absoluta, lo que excluye la calificación de "veto" para un rechazo del texto remitido por el Congreso que no se apoye en la mayoría absoluta del Senado". Así, el Reglamento del Senado, que regula el veto, no se refiere a las enmiendas a la totalidad, que quedan sometidas al régimen jurídico de aquél; y el Reglamento del Congreso prescribe para el veto senatorial que el debate se ajustará a lo establecido para los de totalidad, equiparando veto y enmienda a la totalidad. De todo esto derivó el Tribunal que "la enmienda a la totalidad en el Senado es justamente el veto para el que la Constitución exige mayoría absoluta. Puesto que en este caso hubo propuesta de veto en el Senado, que no obtuvo mayoría absoluta, y no se presentaron enmiendas al texto, el Tribunal concluyó que no

70 STC 97/2002, Fj. 4.

71 STC 97/2002, Fj. 5. El Tribunal se remite a lo afirmado ya en la STC 234/2000, Fj. 12, que hemos recogido en el siguiente apartado, respecto a que la autonomía reglamentaria de las Cámaras está subordinada a lo establecido por la Constitución.

72 STC 97/2002, Fj. 5. 
concurría el supuesto de hecho exigido por el art. 90.2 CE para la nueva lectura en el Congreso ${ }^{73}$.

Esta interpretación tan literal del art. $90 \mathrm{CE}$ también ha sido objeto de ciertas críticas, ya que, en este caso, en el Senado había una mayoría suficiente para haber aprobado una enmienda y haber obligado al Congreso a una nueva lectura, de modo que, aunque no se había producido infracción clara de las normas del procedimiento (la deficiente redacción de algunas de las disposiciones del Reglamento del Senado no contribuyó a resolver el problema), quizás sí cabía entender que "se había alterado el proceso de formación de la voluntad en el Pleno del Senado" ${ }^{74}$.

\subsection{Tramitación urgente de un proyecto de ley}

La jurisprudencia del Tribunal constitucional sobre la fase del procedimiento legislativo en el Senado se completa con la STC 234/2000, relativa a la tramitación urgente de un proyecto de ley en la Cámara Alta. Esta sentencia resuelve un conflicto de atribuciones presentado por el Gobierno contra el Senado en relación con el acuerdo de la Mesa de no admitir a trámite la declaración de urgencia del Gobierno relativa a la tramitación del proyecto de ley orgánica reguladora de la interrupción voluntaria del embarazo.

Las dos partes implicadas en el conflicto coincidieron en reconocer la atribución constitucional al Gobierno de la facultad de declarar urgentes los proyectos de ley, lo cual reduce a veinte días el plazo del que el Senado dispone para vetar o enmendar el proyecto. El Tribunal, por su parte, añadió que "es en el contexto de las facultades constitucionales de las que es titular el Gobierno en relación con el procedimiento legislativo en el que alcanza significado la facultad del Gobierno de declarar la urgencia de los proyectos de ley... en cuanto mecanismo conferido al Gobierno para agilizar la tramitación en el Senado de determinados proyectos de ley." Esta facultad "expresa, en suma, la opción del constituyente por un determinado entendimiento en las relaciones entre las Cortes Generales y el Gobierno" y le permite "actuar sobre el procedimiento legislativo influyendo en su desarrollo cronológico cuando, en su criterio, concurran las circunstancias que asi lo requieran. ${ }^{75}$

El conflicto se planteó en torno a la existencia de límites temporales para la declaración de urgencia por parte del Gobierno. El Senado consideró que la declaración de urgencia del Gobierno debe producirse antes de que el proyecto entre en el Congreso (en este caso la declaración de urgencia del Gobierno y la inadmisión en la Mesa del Senado se produjeron durante la tramitación del pro-

73 STC 97/2002, Fj. 6.

74 A. ARCE JANARIZ, El Parlamento en los Tribunales, op. cit., p. 109 y ss.; E. ARANDA ÁLVAREZ, "Tres casos difíciles en la fase del Senado del procedimiento legislativo", Revista de las Cortes Generales n. ${ }^{\circ}$ 39, 1996, p. 149 y ss.

75 STC 234/2000, Fj. 10. 
yecto en el Congreso). El Gobierno, por su parte, entendió que del tenor del art. 90.3 de la Constitución no resulta dicho límite temporal; que tampoco resulta de un examen teleológico o finalista del mecanismo, pues la urgencia puede ser percibida por el Gobierno iniciada ya la tramitación parlamentaria de un proyecto por cambio de circunstancias; y que existen numerosos precedentes en los que el Gobierno ha declarado la urgencia iniciada ya la tramitación de un proyecto sin que el Senado se haya opuesto nunca ${ }^{76}$.

El Senado apoyó su interpretación en dos argumentos con los que el Tribunal Constitucional no se mostró de acuerdo. En primer lugar, el Senado entendía que, como manifestación de la autonomía parlamentaria, el procedimiento es competencia exclusiva de la Cámara. El Tribunal, sin embargo, consideró que "el art. 72.1 CE recoge, ciertamente, entre otras manifestaciones de la autonomía parlamentaria, la reglamentaria..., que se traduce en la facultad de cada Cámara de dictar sus propios reglamentos sin interferencias de otros órganos o poderes del Estado. Abora bien,... dicha vertiente de la autonomía de las Cámaras, asi como las normas reglamentarias que por éstas se dicten, se encuentran subordinadas o limitadas por la Constitución... El contenido y alcance de la autonomía reglamentaria... han de ser determinados a partir precisamente de cada una de las previsiones del texto constitucional, nunca al margen de ellas". Por ello el Tribunal rechaza que "a partir de una determinada concepción de la autonomía reglamentaria de la Cámara, pueda inferirse un limite temporal al ejercicio por el Gobierno de la facultad de declarar urgentes los proyectos de ley que le confiere el art. $90.3 \mathrm{CE}, \ldots$ al otorgarle tal atribución, el constituyente no ba condicionado ni limitado temporalmente la referida facultad, o tan siquiera ba efectuado remisión alguna para su concreción o desarrollo a la norma reglamentaria de la Cámara, sin que, por lo demás, la autonomía reglamentaria pueda constituir un obstáculo absoluto que impida que el constituyente pueda dotar al Gobierno de un mecanismo que le permita acelerar o abreviar en determinadas circunstancias la tramitación parlamentaria de un proyecto de ley para el desarrollo de su función de dirección politica ${ }^{77}$.

En segundo lugar, el Senado fundaba también el límite temporal en el derecho de la Cámara y sus miembros a ejercer la potestad legislativa y debatir en plazo los proyectos de ley, así como en las exigencias de contradicción efectiva y publicidad del procedimiento legislativo. El Tribunal Constitucional, sin embargo, afirmó que los efectos de la declaración de urgencia de los proyectos de ley han sido previstos constitucionalmente y son los mismos sea cual sea el órgano que declare la urgencia, y que de la valoración que de dichos efectos hace el Senado no cabe inferir en modo alguno el límite temporal que éste postula. En este sentido, y respecto del procedimiento de urgencia, afirmó el Tribunal que "la potestad legislativa que residencia en las Cortes Generales el art. 66.2 CE se ejerce por cada una de las Cámaras que la integran, en la forma y 
con la extensión que el propio texto determina...y, en concreto, por lo que se refiere a la tramitación en el Senado de los proyectos de ley, en los términos en los que establece su art. 90, precepto en el que se señalan sus plazos de tramitación. De modo que la declaración de urgencia por el Gobierno de un proyecto de ley a efectos de su tramitación en dicha Cámara, aun remitido ya el proyecto a las Cortes Generales, si bien abrevia el plazo de ésta, ni le priva del ejercicio de su función legislativa, al incidir el mecanismo conferido al Gobierno sobre la cronología del procedimiento pero no sobre el contenido del proyecto, ni restringe, ni en modo alguno podía hacerlo, el derecho de la Cámara y de sus miembros a tramitar los proyectos de ley en el plazo constitucionalmente establecido, ni, en fin, la reducción del tiempo de tramitación tiene por qué traducirse en merma alguna de los principios constitucionales que ban de informar el procedimiento legislativo en cuanto procedimiento de formación de la voluntad del órgano ${ }^{78}$.

Por todo ello, el Tribunal concluyó que la Mesa del Senado, al no admitir a trámite la declaración de urgencia del Gobierno, había invadido la atribución constitucional que al Gobierno le confiere el art. 90.3 CE.

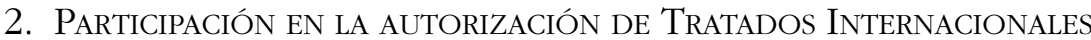

En la reciente STC 155/2005 el Tribunal se pronunció sobre la participación del Senado en el procedimiento de autorización de tratados internacionales, en la misma línea de interpretación literal que ya hemos señalado, aunque en este caso se formularon dos votos particulares que discrepaban precisamente de esa interpretación rígida de los procedimientos parlamentarios. La sentencia resuelve un recurso de inconstitucionalidad presentado contra el Decreto-ley por el que España se adhiere a diversos acuerdos del Fondo Monetario Internacional y contra la Ley de igual contenido resultante de la conversión del Decreto-ley en Ley.

Los recurrentes fundamentaron su recurso, en lo que aquí nos interesa, en que el procedimiento seguido había impedido al Senado participar en el proceso de autorización previa de la firma del Tratado. Los recurrentes afirmaban, de un lado, que el Decreto-ley no es el instrumento jurídico constitucionalmente apropiado para otorgar la autorización previa que exigen aquellos tratados internacionales que suponen asunción de obligaciones financieras para la Hacienda Pública, y, de otro, que la ley en la que éste posteriormente se convierte incurre en el mismo defecto, ya que, de acuerdo con los arts. 94.1 y 74.2 de la Constitución, la firma de ese tipo de tratados requiere la previa autorización de las Cortes Generales, que se adoptará por mayoría de cada una de las Cámaras iniciándose el procedimiento en el Senado y constituyéndose una Comisión Mixta en caso de que no hubiera acuerdo entre ambas ${ }^{79}$.

78 STC 234/2000, Fj. 13.

79 STC $155 / 2005$, antecedentes 3 y 11, Fj. 1. 
En relación con el Decreto-ley, el Tribunal coincidió con los recurrentes en que a este tipo de norma jurídica le están vedadas determinadas materias, entre ellas, la autorización previa para la firma de los tratados internacionales que recoge el art. 94.1 CE. En estos casos la prestación del consentimiento del Estado debe ser autorizada por las Cortes Generales sin que sea posible una prestación de ese consentimiento dispensada por un órgano distinto. El Decreto-ley no es la forma jurídica habilitada para la autorización que requiere el art. 94.1 CE, además de por otros motivos ${ }^{80}$, porque el decreto ley es una fuente normativa propia del Gobierno que para la estabilización de su vigencia en el ordenamiento jurídico sólo precisa de la intervención del Congreso de los Diputados, y no las dos Cámaras que integran las Cortes Generales (no del Senado). "Ni siquiera tras su convalidación parlamentaria es el decreto-ley una forma juridica capaz de dispensar una autorización que sólo pueden brindar las Cortes Generales, pues la convalidación del Congreso de los Diputados nunca puede ser la del órgano complejo en el que se integra junto con el Senado, de manera que no es posible ver en la convalidación un acto equivalente a la autorización requerida por el art. 94.1 CE ${ }^{81}$.

En cuanto a la ley en la que posteriormente se convirtió el Decreto-ley, el Tribunal se pronunció sobre las dos siguientes cuestiones: en primer lugar, sobre la aptitud de la ley para subsanar los defectos constitucionales del Decreto-ley; y, en segundo lugar, sobre su capacidad para servir de cauce a la autorización parlamentaria exigida por el art. 94.1 CE.

En cuanto a la primera cuestión el Tribunal se mostró tajante al afirmar que "la ley no puede en absoluto subsanar el defecto radical padecido por el decreto-ley consistente en ser expresión de una voluntad que en ningún caso puede imputarse a las Cortes Generales, sino, únicamente al Gobierno y, eventualmente, tras la oportuna convalidación, a una sola de las dos Cámaras que integran el conjunto de las Cortes Generales", fundamentalmente porque "las Cortes Generales no autorizarian previamente la integración, como quiere el art. 94.1 CE, sino que validarían una integración ya autorizada por el Gobierno y convalidada por el Congreso de los Diputados, ${ }^{82}$.

En cuanto a la segunda cuestión, sobre la capacidad de la ley para dar la autorización exigida por el art. 94.1, el Tribunal reconoció que la ley es fruto de la voluntad de las Cortes Generales, Congreso y Senado, la misma voluntad que

80 Argumenta el Tribunal que el art. 86.1 CE sólo prevé la figura del Decreto-ley para el dictado de "disposiciones legislativas", categoría jurídica distinta a la de las autorizaciones, y que es claro que no puede conceder una autorización quien debe ser autorizado.

81 STC 155/2005, Fj. 5. Con esta conclusión discrepa D. Jorge Rodríguez-Zapata en su voto particular, en el que afirma que cuando existe extraordinaria y urgente necesidad, como él aprecia en este caso, el Decreto-ley es una fuente reconocida constitucionalmente que atribuye al Gobierno la facultad de dictar normas con rango de ley por vía de sustitución de las Cortes Generales, pues «tras la simple convalidación del mismo, la autorización parlamentaria se habrá producido y se encontrará en una posición similar a la que ostentan las normas que sustituyen a la ley en circunstancias internas, aunque no haya intervenido el Senado" (apdo. 10).

82 STC 155/2005, Fj. 8 . 
la requerida por el art. 94.1 para la autorización previa, así pues en este caso no se lesiona la competencia de las Cortes, sino el procedimiento a través del cual se ejerce dicha competencia. De acuerdo con lo dispuesto en el art. 74.1 la autorización previa de las Cortes "corresponde al ejercicio de una competencia que la Constitución califica de no legislativa, de modo que no resulta constitucionalmente indiferente... (el cauce que se utilice para ejercerla). La cuestión no es ya, en consecuencia, si se ha prescindido o no de la intervención de un órgano, sino si la concreta competencia ejercida por éste lo ba sido por el cauce especificamente previsto por la Constitución a esos efectos. En definitiva, si la Constitución impone... además de una reserva orgánica, una reserva de procedimiento 83 .

El Tribunal reconoció entonces que "para las autorizaciones previstas en el art. $94.1 \mathrm{CE}$, el art. 74.2 establece un procedimiento parlamentario específico $y$ diverso del legislativo ordinario o común, del que singularmente le distingue la circunstancia de que la posición del Senado se define en términos de mayor equilibrio frente a la que habitualmente es propia del Congreso de los Diputados. Así, mientras que en el procedimiento legislativo es norma que, de acuerdo con el art. 90.2 CE, las discrepancias entre ambas Cámaras puedan resolverse en último término por decisión de la mayoría simple de la Cámara baja — también cuando el Senado ejerce un veto...-, en el caso del art. 94.1 se prevé que las discrepancias se superen por medio de una Comisión mixta compuesta de igual número de Diputados y Senadores, cuya propuesta debe ser aprobada por la mayoría de cada Cámara, imponiéndose finalmente, si la discrepancia persiste, la del Congreso de los Diputados, pero sólo y siempre por mayoría absoluta (art. $74.2 \mathrm{CE}$ ), ${ }^{84}$.

Continuó el Tribunal admitiendo que "esa potenciación de la voluntad del Senado, en comparación con la más reducida importancia que se le atribuye en el procedimiento legislativo..., determina el proceso de formación de la voluntad parlamentaria en términos que se separan de cuanto es común en el conjunto de los procedimientos de las Cortes Generales, confiriéndose a la participación de la Cámara alta en aquel proceso una relevancia verdaderamente excepcional en nuestro sistema parlamentario, caracterizado por un notorio bicameralismo imperfecto... El procedimiento del art. 74.2 CE ofrece, en suma, caracteres de entidad relevante para configurarlo como reservado para la adopción del acuerdo exigido por el art. 94.1 CE, de manera que, en principio, es obligado entender que la autorización parlamentaria previa a la prestación del consentimiento internacional del Estado ha de conformarse por ese específico procedimiento,, 85 .

83 STC $155 / 2005$, Fj. 9.

84 STC $155 / 2005$, Fj. 9.

85 STC $155 / 2005$, Fj. 9. Discrepa de esta opinión D. Jorge Rodríguez-Zapata en su voto particular, en el que afirma que "las Cortes Generales son libres de administrar sus propios procedimientos y no corresponde al Tribunal encorsetar al Parlamento estableciendo reservas de procedimiento para las que no se ofrece un apoyo inequívoco en la Norma Fundamental,, y recuerda la práctica de las "leyes de autorización" (apdo. 4). 
Afirmado esto, el Tribunal comprobó que la ley recurrida no sólo contenía la autorización a la firma del Tratado sino también disposiciones que establecen normas puramente internas relativas a la ejecución del mismo y afirmó que en estos casos se impone una duplicidad de procedimientos: uno para otorgar la autorización previa a la firma del Tratado, que no es el adecuado para aprobar disposiciones normativas como las mencionadas, y otro, el procedimiento legislativo, para aprobar dichas disposiciones. Sobre esta base declaró inconstitucional la autorización contenida en la ley recurrida, por vulneración de los arts. 94.1 y $74.2 \mathrm{CE}^{86}$, y constitucionales las disposiciones contenidas en la ley diferentes de la autorización ${ }^{87}$.

\section{DERECHO PROCESAL CONSTITUCIONAL Y SENADO}

En algunos de los recursos relativos al Senado que el Tribunal Constitucional ha tenido que resolver se planteaban, además de las cuestiones de fondo, cuestiones procesales relevantes a las que nos referiremos brevemente a continuación.

\section{LA LEGITIMACIÓN DE LOS SENADORES PARA PRESENTAR RECURSO DE INCONSTITUCIONALIDAD}

En la tramitación de un recurso de inconstitucionalidad presentado por un grupo de senadores, el Abogado del Estado alegó que procedía desestimar el recurso por falta de legitimación sobrevenida en las personas de los actores, dado que un mes después de presentado el recurso se disolvieron las Cortes Generales y los recurrentes perdieron su condición de senadores, por lo que debía aplicarse entonces lo dispuesto en los arts. $9 .^{\circ}$ y $5 .{ }^{\circ}$ de la Ley de Enjuiciamiento Civil, por remisión del art. 80 de la LOTC ${ }^{88}$.

El Tribunal Constitucional, sin embargo, entendió que la remisión de la LOTC a la Ley de Enjuiciamiento Civil hay que interpretarla en el sentido de que ésta será aplicable en la medida en que no vaya contra la LOTC y sus principios inspiradores. En concreto, la legitimación para presentar un recurso de inconstitucionalidad debe interpretarse desde la perspectiva de que el Tribunal

86 D. Javier Delgado Barrio formuló voto particular a esta sentencia por considerar que, a pesar de lo afirmado en los FJ 9 y 10, la ley recurrida no vulneró el art. 94.1 ni el 74.2 CE; el art. 94.1, porque consta la voluntad de ambas Cámaras de otorgar la autorización exigida por dicho precepto; y el art. 74.2, porque, aunque se haya seguido el procedimiento legislativo, en modo alguno se han infringido sus exigencias procedimentales ni minorado la fortalecida posición del Senado en este campo (el Senado se pronunció por mayoría y no hubo desacuerdo entre ambas Cámaras), objetivo fundamental del precepto, sin que por tanto haya que plantearse la existencia de una posible alteración en la formación de la voluntad de las Cámaras.

87 STC 155/2005, Fj. 10.

88 STC 86/1982, Antecedente 4. 
garantiza la supremacía de la Constitución, un interés público objetivo; en consecuencia, "cuando cincuenta senadores o más deciden formular un recurso de inconstitucionalidad están poniendo de manifiesto la existencia de un interés público objetivo en que el Tribunal Constitucional desarrolle su función de garantizar la supremacía de la Constitución mediante el enjuiciamiento de la ley impugnada. Por eso la pérdida de la condición de senador no da lugar a la aplicación del art. 9.5.', en conexión con el 5, de la Ley de Enjuiciamiento Civil, dada la subsistencia del interés público objetivo en determinar si la ley impugnada es conforme o no con la Constitución, ${ }^{89}$.

\section{Recursos contra actos del Senado}

\subsection{Conflictos de atribuciones}

El Tribunal Constitucional únicamente ha resuelto dos conflictos de atribuciones relativos a las competencias de las Cortes Generales, y en los dos el Senado era parte demandada.

a) En el primer caso el Tribunal Constitucional resolvió varios conflictos de competencias presentados por el Consejo General del Poder Judicial (CGPJ) contra las decisiones de las Cámaras que condujeron a la aprobación de la Ley Orgánica del Poder Judicial, es decir, no contra la Ley Orgánica, sino contra la decisión del Pleno del Congreso de aprobar el proyecto de ley, la decisión del Senado por la que se aprobaron ciertas enmiendas al proyecto y la decisión final del Congreso de aprobar el proyecto de ley ${ }^{90}$.

En primer lugar el Tribunal se pronunció sobre la posibilidad de plantear un conflicto de este tipo contra las decisiones adoptadas a lo largo de un procedimiento legislativo, y respecto a los actos recurridos el Tribunal afirmó que "agotaron su eficacia en lo que tuvieron de manifestación de voluntad de cada Cámara y de presupuesto para la continuación del procedimiento legislativo, pero al carecer de la condición de disposición normativa, no pudieron entrañar por si mismos despojos competenciales algunos, al carecer de virtualidad, agresiva, actual y efectiva, sobre atribuciones de otro órgano constitucional. Ello ha de afirmarse incluso de la votación final del Congreso para ratificar las enmiendas del Senado" ${ }^{11}$.

El Tribunal no dejó de reconocer que estas consideraciones no llevarían necesariamente a la inadmisibilidad del recurso, porque, una vez vigentes las disposiciones legislativas a que dieron lugar los actos recurridos, la lesión adquirió actualidad y eficacia. "Sin embargo, admitir esto, supone una desfiguración manifiesta del proceso conflictual,; en primer lugar, porque aunque los

89 STC 86/1982, Fj. 2.

90 STC 45/1986, antecedentes 1,6 y 9 .

91 STC 45/1986, Fj. 2. 
recurrentes afirmen no atacar la ley, sin ella los actos parlamentarios recurridos no podrían producir lesión alguna; y, en segundo lugar, porque el conflicto habría de entenderse planteado no frente a cada una de las Cámaras, sino frente al "órgano de estructura global que son las Cortes Generales" "2.

Así pues el conflicto debe entenderse planteado frente a la ley, pero ello llevó entonces al Tribunal a preguntarse "si en las relaciones entre órganos constitucionales del Estado puede admitirse en abstracto la hipótesis de una invasión de atribuciones "sub specie legis" que, constitutiva de un vicio de la ley por "defectos de competencia", pudiera ser residenciado ante el Tribunal en el conflictos de atribuciones". Consideró el Tribunal que este planteamiento "supone un análisis excesivamente general, y que puede resultar en estos momentos no solo prematuro sino además innecesario. No obstante, no deben desconocerse las dificultades de encaje que podría tener la disposición legislativa dentro del cauce procesal abierto en los arts. 73 y ss. de la LOTC y que existen cauces específicos adecuados para el control de la constitucionalidad del contenido de la ley. La propia regulación del procedimiento conflictual lo hace dificilmente practicable como reacción frente a una presunta invasión de atribuciones por obra del legislador. Así, "siendo la ley acto complejo de formación bicameral y imputable, en su adopción, a las Cortes Generales, tendría que estar este órgano plural pasivamente legitimado como tal en este procedimiento. El intento de un doble requerimiento $y$ de una también doble acción conflictual supone reconocer la falta de legitimación pasiva del órgano plural en sí mismo considerado. La consideración aislada de las Cámaras, sin embargo, las hace impotentes para reparar hipotéticas lesiones derivadas de un acto complejo, y en particular para responder al requerimiento previo y "revocar" la decisión invasora, no imputable, aisladamente, a ninguna de las Cámaras, y por ello no reparable aisladamente por una $u$ otra de ellas, $" 93$.

En segundo lugar, a pesar de todas las consideraciones anteriores el Tribunal admitió el conflicto planteado y entró a examinar si se daba el supuesto de este tipo de conflictos. El Consejo General del Poder Judicial consideraba invadida o indebidamente asumida la competencia para elegir a los doce vocales del CGPJ que, conforme a una enmienda introducida por el Senado, se atribuía al Congreso, para elegir a seis de los vocales, y al Senado, para elegir a los otros seis. El Tribunal, sin embargo, entendió que no existía verdadero conflicto de competencias porque la competencia controvertida difícilmente la podía reclamar como propia el CGPJ, cuando "este tipo de proceso conflictual requiere no sólo el estimar ejercidas antijurídicamente por otro órgano judicial unas determinadas atribuciones, sino, además, el que el órgano que plantea el conflicto asegure y defienda ser titular de la atribución constitucionalmente controvertida ${ }^{94}$. Por ello, sin pronunciarse sobre la asun- 
ción de dicha competencia por el Senado, el Tribunal desestimó el conflicto de atribuciones ${ }^{95}$.

b) Al segundo conflicto de atribuciones resuelto por el Tribunal Constitucional ya nos hemos referido anteriormente, se trata del caso en el que el Senado no admitió a trámite la declaración de urgencia del Gobierno relativa a la tramitación de un proyecto de ley. En la sentencia que lo resuelve el Tribunal revisa sus afirmaciones de la sentencia anterior relativas a la delimitación del objeto del conflicto y amplía la posibilidad de que se planteen conflictos de atribuciones contra actos de las Cámaras. Frente a lo afirmado anteriormente ("en los conflictos de atribuciones el legislador no ha admitido otro supuesto que el de la estricta usurpación de funciones $)^{96}$, aquí el Tribunal admite que un acuerdo de la Mesa puede ser objeto de un conflicto de atribuciones, a pesar de que "el órgano demandado no ha(ya) ejercido una atribución que sea reivindicada como propia por el órgano demandante, el conflicto se admite porque la Mesa "ha frustrado el ejercicio de una atribución que el Gobierno considera como propia" y "atemperando ahora la delimitación que de su objeto (del conflicto de atribuciones) se bizo en la mencionada Sentencia (STC 45/86), procede apreciar que tanto la decisión impugnada como la pretensión deducida en este supuesto han de considerarse suficientemente adecuadas a la estructura y función del conflicto de atribuciones, toda vez que lo que se pretende es preservar el ámbito de atribuciones de los órganos constitucionales mencionados en el art. 59.3 LOTC.97.

\subsection{Recursos de amparo contra actos no de ley}

La STC 121/97, por la que el Tribunal resuelve un recurso de amparo contra las Normas reguladoras de las elecciones a la Junta de personal de las Cortes Generales, y a la que ya nos hemos referido anteriormente, contiene afirmaciones determinantes respecto a los procedimientos de amparo contra actos no de ley.

En primer lugar, en esta sentencia el Tribunal aclaró que existen dos vías de amparo para recurrir contra actos no de ley de las Cortes Generales: la vía del art. 42 LOTC, para recurrir contra actos típicamente parlamentarios, la úni-

95 STC 45/1986, Fj. 5. El Tribunal afirmó que la atribución de elegir a los miembros del CGPJ, aunque está referida al modo de integrarse este órgano, no se reivindica para el Consejo, ni siquiera para el Poder judicial como tal, sino respecto a la intervención en el proceso de designación de los jueces y magistrados de carrera, de modo que hay una "falta de correspondencia entre órgano actor y sujeto titular de la atribución supuestamente invadida que el actor trata de justificar con argumentaciones que el Tribunal no comparte.

96 STC 45/1986, Fj. 4: "A diferencia de los conflictos interterritoriales en los que este Tribunal ha admitido supuestos de lesión por simple menoscabo — no por invasión - de competencias ajenas, en los conflictos entre órganos constitucionales el legislador no ha admitido otro supuesto que el de la estricta usurpación de atribuciones".

97 STC 234/2000, Fj. 5. 
ca que se había utilizado hasta ese momento; y la vía del art. 43 para recurrir actos de administración.

Así, respecto a la vía del art. 42 afirmó que "el amparo, por así decir, directo previsto en el art. 42 LOTC queda reservado a los "actos y decisiones sin valor de ley" emanados de las Cámaras, de naturaleza típicamente parlamentaria y que, por ser expresión ad intra de su autonomía como órganos constitucionales, resultan "excluidos del conocimiento, verificación y control, por parte de los Tribunales, tanto de los ordinarios como de este Tribunal", a no ser que afecten a un derecho o libertad susceptible de protección a través del recurso de amparo (art. 53.2 CE), en cuyo caso "sale o trasciende de la esfera irrevisable propia de los interna corporis acta" correspondiendo su examen a este Tribunal..." ${ }^{98}$.

Las normas recurridas, reguladoras de las elecciones a junta de personal, serían, sin embargo, recurribles por la vía del art. 43. "No siendo la resolución impugnada susceptible de ser calificada como interna corporis acta, por recaer sobre una materia — la de personal — sometida al control de la jurisdicción contencioso-administrativa, procedía procesalmente equipararla a aquellas otras disposiciones normativas sin valor de ley dictadas por los demás poderes públicos y, en consecuencia, estimar que su eventual impugnación a través del recurso de amparo únicamente era factible con arreglo al cauce establecido en el art. 43 LOTC L9. $^{9}$.

Además de diferenciar las dos vías procesales anteriores, en esta sentencia el Tribunal se pronunció sobre las disposiciones generales recurribles en amparo, afirmando que "no todas las disposiciones generales de las Cámaras pueden entenderse excluidas del conocimiento a través del recurso de amparo. En puridad, la exclusión clara que hace el art. 42 LOTC es respecto a las disposiciones con fuerza o valor de ley, susceptibles de ser objeto de recurso de inconstitucionalidad de acuerdo al art. 161.1. a CE y el art. 27 de la misma Ley orgánicas. El Tribunal se remitió a lo afirmado en otras sentencias, que la lesión de un derecho fundamental puede tener su origen directo e inmediato en una disposición general (no en un acto concreto de aplicación de la misma), de modo que en determinados casos dicha norma puede recurrirse en amparo ${ }^{100}$.

Finalmente el Tribunal afirmó que no importa que la disposición impugnada sea reproducción o remita a lo dispuesto en una norma con valor de ley, como alegaba el Abogado del Estado, pues de ello sólo derivaría la obligación, en caso de estimar la demanda, de elevar al Pleno cuestión de inconstitucionalidad respecto a esa norma ${ }^{101}$.

98 STC 121/1997, Fj. 3.

99 STC 121/1997, Fj. 3.

100 STC 121/1997, Fj. 5, citando las STC 118/1998 y 192/1991.

101 STC 121/1997, Fj. 5. 


\section{ANEXO}

\section{Sentencias Que ReSuelven RECURSOS DE inCONSTITUCIONALIDAD QUE AFECTEN AL SENADO}

STC 40/1981, de 18 de diciembre, que resuelve el recurso inconstitucionalidad promovido por el Abogado del Estado, en representación del Presidente del Gobierno, contra la Ley del Parlamento Vasco 4/1981 sobre designación de Senadores representantes de Euskadi.

STC 194/2000, de 19 de julio, que resuelve el recurso inconstitucionalidad promovido por setenta y ocho Diputados del Congreso en relación con la disposición adicional cuarta de la Ley 8/1989, de 13 de abril, de Tasas y Precios Públicos.

STC 97/2002, de 25 de abril, que resuelve los recursos de inconstitucionalidad promovidos por el Gobierno y el Parlamento de las Illes Balears en relación con la Ley 26/1995, de 31 de julio, por la que se declaran reserva natural las Salinas de Ibiza, las Islas de Freus y las Salinas de Formentera.

STC 155/2005, de 9 de junio, que resuelve los recursos de inconstitucionalidad acumulados promovidos por más de cincuenta Diputados contra el Decreto-ley 14/1998, de 9 de octubre, de adhesión de España a diversos acuerdos del Fondo Monetario Internacional y contra la Ley 13/1999, de adhesión de España a diversos acuerdos del Fondo Monetario Internacional.

\section{ReCURSOS DE INCONSTITUCIONALIDAD PRESENTADOS POR SENADORES}

En la I Legislatura: Recurso de inconstitucionalidad n. ${ }^{\circ}$ 186/1980, contra las Leyes de Bases de Régimen Local de 17-7-1945 y 3-12-1953, y otras disposiciones; Recurso de inconstitucionalidad n. ${ }^{\circ}$ 189/1980, contra Ley Orgánica 5/1980 reguladora del Estatuto de Centros Escolares; Recurso de inconstitucionalidad n. ${ }^{\circ}$ 2901982, contra la Ley 11/1982 supresora del Organismo Autónomo Medios de Comunicación Social del Estado.

En la II Legislatura: Recurso de inconstitucionalidad n. ${ }^{\circ} 685 / 1984$, contra la Ley de Andalucía 8/1984 de Reforma Agraria; Recurso de inconstitucionalidad n. ${ }^{\circ}$ 695/1985, contra la Ley 10/1985 de modificación parcial de la Ley General Tributaria; Recurso de inconstitucionalidad n. ${ }^{\circ}$ 944/1985, contra la Ley 29/1985 de Aguas.

En la III Legislatura: Recurso de inconstitucionalidad n. ${ }^{\circ} 887 / 1986$, contra la Ley 1/1986 de Extremadura sobre la Dehesa de dicha Comunidad Autónoma; Recurso de inconstitucionalidad n. ${ }^{\circ} 11 / 1984$, contra la Ley 11/1983 Valenciana por la que se declaran de interés general para dicha Comunidad funciones propias de las Diputaciones Provinciales; Recurso de inconstitucionalidad n. ${ }^{\circ}$ 119/1984, contra la Ley Vasca 27/1983, de Relaciones entre las Instituciones Comunes de la Comunidad Autónoma y los Organos Forales de sus Territorios Históricos; Recurso de inconstitucionalidad n. ${ }^{\circ}$ 1880/1989, contra la Ley 8/1989 
de Galicia de delimitación y coordinación de las competencias de las Diputaciones Provinciales de Galicia.

En la IV Legislatura: Recurso de inconstitucionalidad n. ${ }^{\circ}$ 190/1991, contra la Ley 2/1991 sobre derechos de información de los representantes de los trabajadores en materia de contratación; Recurso de inconstitucionalidad n. ${ }^{\circ}$ 746/1991, contra la Ley 8/1990 de caza de Extremadura; Recurso de inconstitucionalidad n. ${ }^{\circ}$ 2709/1992, contra la Ley 4/1992 de Policía del País Vasco; Recurso de inconstitucionalidad n. ${ }^{\circ}$ 433/1993, contra la Ley 38/1992 de Impuestos Especiales.

En la V Legislatura: Recurso de inconstitucionalidad n. ${ }^{\circ} 2299 / 1993$, contra la Ley de la Rioja 2/1993, de Presupuestos; Recurso de inconstitucionalidad n. ${ }^{\circ}$ 2300/1993, contra la Ley 5/1993, de liquidación definitiva de la participación de las Corporaciones locales en los Tributos del Estado de 1990; Recurso de inconstitucionalidad n. ${ }^{\circ}$ 3584/1994, contra el Decreto-Ley 8/1994, que suprime las Cámaras Oficiales de la Propiedad Urbana y su Consejo Superior.

En la VI Legislatura: Recurso de inconstitucionalidad n. ${ }^{\circ}$ 3449/1997, contra diversas disposiciones del Reglamento de la Asamblea de Extremadura; Recurso de inconstitucionalidad n. ${ }^{\circ}$ 673/1998, contra una disposición de la Ley 6/1989, de la Función Pública Vasca; Recurso de inconstitucionalidad n. ${ }^{\circ}$ 2136/1998, contra un artículo de la Ley cántabra 1/1998, de regularización de personal de la Diputación Regional de Cantabria; Recurso de inconstitucionalidad n. ${ }^{\circ}$ 2544/1998, contra la Ley 1/1998 de Fundaciones de la Comunidad de Madrid.

En la VII Legislatura no se presentó ningún recurso de inconstitucionalidad.

En la VIII Legislatura: Recurso de inconstitucionalidad n. ${ }^{\circ}$ 5598/2004, contra el Decreto-Ley 2/2004 que modifica la Ley 10/2001 del Plan Hidrológico Nacional; Recurso de inconstitucionalidad n. ${ }^{\circ} 7826 / 2004$, contra la Ley de Cantabria 2/2004, del Plan de Ordenación del Litoral; Recurso de inconstitucionalidad n. ${ }^{\circ}$ 2046/2005, contra un artículo de la Ley de Cantabria 7/2004 de Medidas Administrativas y Fiscales.

\section{SENTENCIAS que RESUELVEn RECURSOS DE AMPARO FRENTE a ACTOS DEL SENADO}

STC 90/1985, de 22 de julio, que resuelve el recurso de amparo promovido por Don Francisco Gracia Guillén contra el Acuerdo del Pleno del Senado de 23 de noviembre de 1983, por el que se denegó el suplicatorio para procesar a un Senador.

STC 206/1992, de 27 de noviembre, que resuelve el recurso de amparo promovido por Don Juan Hormaechea Cazón, Presidente del Consejo de Gobierno de la Diputación Regional de Cantabria, y por el Consejo de Gobierno de dicha Comunidad, contra el Acuerdo del Pleno del Senado de 15 de marzo de 1989, por el que se denegó el suplicatorio para procesar a un Senador.

STC 243/1988, de 19 de diciembre, que resuelve el recurso de amparo promovido por Don José García Montón y Don Angel Crespo Bernardo contra 
el Acuerdo del Pleno del Senado de 18 de marzo de 1987, que denegó el suplicatorio para proceder civilmente contra un Senador.

STC 139/1988, de 8 de julio, que resuelve el recurso de amparo promovido por Don Nicolás Pérez Serrano Jáuregui contra el Acuerdo de las Mesas del Congreso y el Senado de 21 de noviembre de 1985, por el que se modifica el Estatuto del Personal de las Cortes Generales.

STC 205/1990, de 13 de diciembre, que resuelve el recurso de amparo promovido por el Grupo Parlamentario del Senado Convergencia i Unió contra los acuerdos de la Mesa del Senado de 10 de octubre y 15 de noviembre de 1988 en los que se resuelve no admitir a trámite la moción presentada por dicho Grupo sobre uso de lenguas oficiales y desestimar la solicitud de reconsideración del acuerdo.

STC 121/1997, de 1 de julio, que resuelve el recurso de amparo promovido por la Federación Sindical de Administración Pública de Comisiones Obreras contra la Resolución de los Presidentes del Congreso de los Diputados y el Senado de 20 de mayo de 1998, por la que se dictan las Normas Reguladoras de las elecciones a la Junta de Personal de las Cortes Generales.

\section{Sentencias Que Resuelven ReCursos De amparo PResentados POR CANDIDATOS AL SENADO}

STC 45/1983, de 25 de mayo, que resuelve el recurso de amparo promovido D.Feliciano Correa Gamero contra la Sentencia que la Sala de lo Contencioso-Administrativo de la Audiencia Territorial de Cáceres pronunció el 9 de octubre de 1982, en proceso contencioso electoral.

STC 21/1984, de 16 de febrero, que resuelve el recurso de amparo promovido D. Fernando Luis Peligero Escudero contra la Sentencia de la Sala Quinta del Tribunal Supremo de 5 de enero de 1983, dictada en proceso electoral.

STC $27 / 1990$, de 22 de febrero, que resuelve el recurso de amparo promovido por el representante de la candidatura al Senado del Partido Popular en Avila y por D. Agustín Díaz de Mera, candidato al Senado por dicho Partido, contra la Sentencia de 2 de diciembre de 1989 de la Sala de lo Contencioso-Administrativo del Tribunal Superior de Justicia de Castilla y León.

STC 131/1990, de 16 de julio, que resuelve el recurso de amparo promovido por el representante de la candidatura al Senado del Partido Popular en Avila y por D. Agustín Díaz de Mera, candidato al Senado por dicho Partido, contra la Sentencia de 28 de febrero de 1990 de la Sala de lo Contencioso-Administrativo del Tribunal Superior de Justicia de Castilla y León.

STC 166/1993, de 20 de mayo, que resuelve el recurso de amparo promovido por D. Dimas Martín Martín contra la Sentencia de la Sala de lo Contencioso-Administrativo del Tribunal Superior de Justicia de Canarias de 14 de mayo de 1993.

STC 26/2004, de 26 de febrero, que resuelve el recurso de amparo promovido por el representante electoral general de Falange Auténtica contra la sen- 
tencia del Juzgado de lo Contencioso-Administrativo n. ${ }^{\circ} 1$ de Granada, de 20 de febrero de 2004, por la que se inadmitió la candidatura al Senado del citado Partido.

\section{SENTENCIAS Que RESUELVEN RECURSOS DE AMPARO PLANTEAdOS CON RELACIÓN A LA DESIGNACIÓN DE SENADORES AUTONÓMICOS}

STC 76/1989, de 27 de abril, que resuelve el recurso de amparo promovido por Don Adolfo Díaz-Ambrona Bardají, contra la resolución adoptada el 28 de julio de 1987 por la Mesa de la Asamblea de Extremadura y contra el Acuerdo del Pleno de dicha Asamblea del 31 de julio de 1987.

STC 149/1990, de 1 de octubre, que resuelve el recurso de amparo promovido por Don Carlos Rici Ferrer contra las resoluciónes de la Mesa del Parlamento de las Islas Baleares, de 8 y 14 de noviembre de 1989.

STC 4/1992, de 13 de enero, que resuelve el recurso de amparo promovido por el Grupo Parlamentario Popular de la Asamblea de Madrid contra los Acuerdos de la Mesa y el Pleno de dicha Asamblea, de 8 y 16 de julio de 1991, relativos a la distribución del número de Senadores que corresponde a cada Grupo Parlamentario y a su designación.

\section{Sentencias Que Resuelven otros ReCursos De amparo PRESENTADOS POR SENADORES}

STC 47/1982, de 12 de julio, que resuelve el recurso de amparo promovido por Don Miguel Castells Arteche, contra la resolución de la Sala Segunda del Tribunal Supremo de Justicia de 4 de diciembre de 1981, por la que se denegó la admisión a trámite del escrito formulando recusación contra varios Magistrados de dicha Sala.

STC 51/1985, de 10 de abril, que resuelve el recurso de amparo promovido por Don Miguel Castells Arteche, contra la Sentencia dictada por la Sala Segunda del Tribunal Supremo el 31 de octubre de 1983, en la causa seguida contra él por delito de injurias al Gobierno.

STC 74/1991, de 8 de abril, que resuelve el recurso de amparo promovido por tres Senadores electos, contra la decisión del Presidente del Senado de 2 de octubre de 1990, por la vulneración del artículo 23.2 CE en relación con el artículo $14 \mathrm{CE}$.

STC 151/1999, de 14 de septiembre de 1999, que resuelve el recurso de amparo promovido por un Senador contra la sentencia dictada por la Sala Segunda del Tribunal Supremo de 27 de octubre de 1994, en la causa seguida contra él por distintos delitos.

STC 124/2001, de 4 de junio, que resuelve el recurso de amparo promovido por Don José María Sala i Griso, contra la Sentencia dictada por la Sala Se- 
gunda del Tribunal Supremo el 28 de octubre de 1997, en la causa seguida contra él por distintos delitos.

\section{Sentencias que Resuelven CONFlictos De ATRIBUCiOnes Que AFECTEN al SENADO}

STC 45/1986, de 17 de abril, que resuelve los conflictos acumulados entre órganos constitucionales promovidos por el Consejo General del Poder Judicial contra determinados preceptos incluidos en los proyectos de la Ley Orgánica del Poder Judicial.

STC 234/2000, de 3 de octubre, que resuelve el conflicto entre órganos constitucionales promovido por el Gobierno contra el Senado en relación con el Acuerdo de la Mesa de la Cámara Alta, de 29 de noviembre de 1995, de no admitir a trámite la declaración de urgencia del Gobierno relativa a la tramitación del proyecto de Ley Orgánica sobre regulación de la interrupción del embarazo.

ABSTRACT. This paper analyses the cases of the Constitutional Court related to the Senate in its last twenty five years of activity. The first conclusion is that there are not many cases related to the Senate, but those analysed are enough representative of the main task given to the Senate by the Constitution. Mainly: senators status, internal organisation, functions and powers. There is a parallelism between the jurisprudence of that related to the Senate and that to the Congress and to the Parliaments of the Autonomy Regions (Comunidades Autonomas), although there are some cases only referred to the Senate, especially the cases referred to the Senate's powers, as far as both Chambers have different powers. The paper also focuses on the Constitutional Process Law applicable to the questions referred. 